\title{
Comparative Fuel Economy, Cost and Emissions Analysis of A Novel Mild Hybrid and Conventional Vehicles
}

\author{
Mohamed Awadallah, Peter Tawadros, Dr Paul Walker, and Prof. Nong Zhang
}

\begin{abstract}
Mild hybrid vehicles have been explored as a potential pathway to reduce vehicle emissions cost-effectively. The use of manual transmissions to develop novel hybrid vehicles provides an alternate route to producing low cost electrified powertrains. In this paper, a comparative analysis examining a conventional vehicle and a Mild HEV is presented. The analysis considers fuel economy, capital and ongoing costs, and environmental emissions, and includes developmental analysis and simulation using mathematical models. Vehicle emissions (nitrogen oxides, carbon monoxide and hydrocarbons) and fuel economy are computed, analysed, and compared using a number of alternative driving cycles and their weighted combination. Different driver styles are also evaluated. Studying the relationship between the fuel economy and driveability, where driveability is addressed using fueleconomical gear shift strategies. Our simulation suggests the hybrid concept presented can deliver fuel economy gains of between 5 and 10 percent, as compared to the conventional powertrain.
\end{abstract}

Keywords: Automotive transmissions; Fuel economy; Mild hybrid electric vehicle (MHEV); Operation cost; Passenger vehicles; Powertrain; Torque gap filling.

\author{
Authors \\ Mohamed Awadallah, Mohamed.M.Awadallah@student.uts.edu.au; eng.m.zakaria@gmail.com; \\ Peter Tawadros, Peter.Tawadros@uts.edu.au; \\ Dr Paul Walker, Paul.Walker@uts.edu.au; \\ Prof. Nong Zhang, Nong.Zhang@uts.edu.au; \\ Faculty of Engineering and Information Technology, School of Mechanical and Mechatronic \\ Systems, University of Technology Sydney, 81 Broadway, Ultimo, NSW 2007, Australia.
}

\section{INTRODUCTION}

In the face of ever-tightening emissions regulations, automotive researchers and OEMs the world over are racing to develop new, complex control methods of multi-modal hybrid powertrain architectures $(1,2)$ or eke minuscule but repeatable gains in efficiency out of a vehicle through careful and painstaking review of construction and optimization $(3,4)$. This activity is a recognition of the significant impact the transportation sector has in worldwide energy consumption and greenhouse gas emissions (GHG), accounting for some $33.7 \%$ of GHG emissions and $27 \%$ of worldwide energy consumption (5). Developed markets of the US, Japan, and Europe, as well as other OECD countries, are benefiting directly from being the primary purchasers of these new low-emissions, zero-emissions, or partial-zero-emissions vehicles. According to the OECD (6), many of the 34 member countries have consistently achieved reductions in atmospheric pollutant levels since 2005. However, the world still faces problems of climate change and oil depletion, and the uptake of modern vehicle technology has altered the distribution of air pollution. If we are to inspect the distribution of air pollution levels in cities worldwide, it is no longer these developed regions that are the problem. A clear trend describing increasing mortality in the developing, low-income cities of the world is emerging (7). The inhabitants of these cities, whether they are limited by 
circumstance or availability, are also those least likely to be able to purchase a new lowemissions vehicle. A new problem has therefore emerged for engineers to solve. That is: how can we bring the benefits of low-emissions technology to the people who need it the most, but can afford it the least?

This question will be explored through the framework of a prototype vehicle, which is designed to bring the benefits of hybrid vehicle architecture to developing markets at an attractive price-point, and with attractive low-cost features suitable for these particular markets. A financial analysis is conducted in which the vehicle production cost and total operating cost are estimated. This is accomplished by breaking the mild hybrid vehicle and conventional vehicle down into major components or systems and accounting for the price difference between the conventional vehicle and the hybrid. By examining the difference in price rather than the absolute cost of ownership of each vehicle, variations in energy costs are highlighted and quantified (8). Further development potential and improvements in the economy through optimisation of the electrified powertrain are also discussed.

The main research objective herein is to develop a simple, cost-effective mild hybrid powertrain system based on a conventional manual transmission (MT). This is structured to provide a vehicle that is marketable to developing regions where there is the poor uptake of hybrid and electric vehicles, owing to additional costs, and a relatively high level of air pollution. The configuration is designed as a post-transmission parallel hybrid electric vehicle, combining a four-cylinder engine, and five-speed manual transmission. The design is designed to be easily upgradeable to an AMT as development work progresses, which is a goal of this body of work. The secondary power source, in the form of an electric motor (EM), is rigidly coupled to the MT output shaft, inline with the prop shaft and prior to the final drive system. The rigid coupling allows a high degree of fidelity when calibrating the torque-hole filling algorithm, and simplifies the kinematic model. There are a number of existing sources of literature similar to what is studied in this paper (9-11). Baraszu (9) is the most similar representation of the propose powertrain. However, the system in this paper does away with the clutch used to isolate the motor. Furthermore, this paper is focused on the social and environmental effects of the technology, as much as the technical side, as the impact of such system has not been fully investigated.

The paper is organised as follows: Section 2 is a discussion of the energy management strategy and the different operation modes of the vehicle. The rule-based controller design is presented and explained. The vehicle model is established in Section 3, followed by the simulation results under different conditions. Fuel economy and the methods of evaluation are detailed in section 4. Cost analysis and simulation results are presented in section 5. Finally, the conclusion is made in section 6.

\subsection{Architecture and Development Approach}

Partial drivetrain electrification is a cost-effective means of improving fuel economy. By utilising an EM to supplement the ICE, varying power demands may be more efficiently met without sacrificing vehicle performance (12-14). However, the advent of a mild hybrid electric powertrain represents the greatest opportunity for improvement of driving comfort, shifting quality, fuel economy and improved driveability with low manufacturing costs. Typically, mild hybrid vehicles deliver between five and ten percent better fuel economy than equivalent conventional vehicles $(15,16)$. The electrified side of the powertrain can serve multiple functions, including engine start-stop, motor-assist, as well as regenerative braking. The hybrid configuration specified in this paper is based on a low-powered, output shaftmounted electric motor, connected to the output shaft of a MT and powered with a controlled 
power source. This configuration allows for increased functionality of the powertrain along with a reduction in the torque hole during gear changes, improving driving performance. Because the motor is mounted after the gearbox, over-rev protection is not required. Instead, the engine rev limiter and appropriate gearing ratios are used to naturally limit motor speed. High-quality shift control is critical to minimising the gear-shift torque hole and vibration of the powertrain (17). Figure 1 presents the layout of a mild hybrid; MT equipped powertrain.

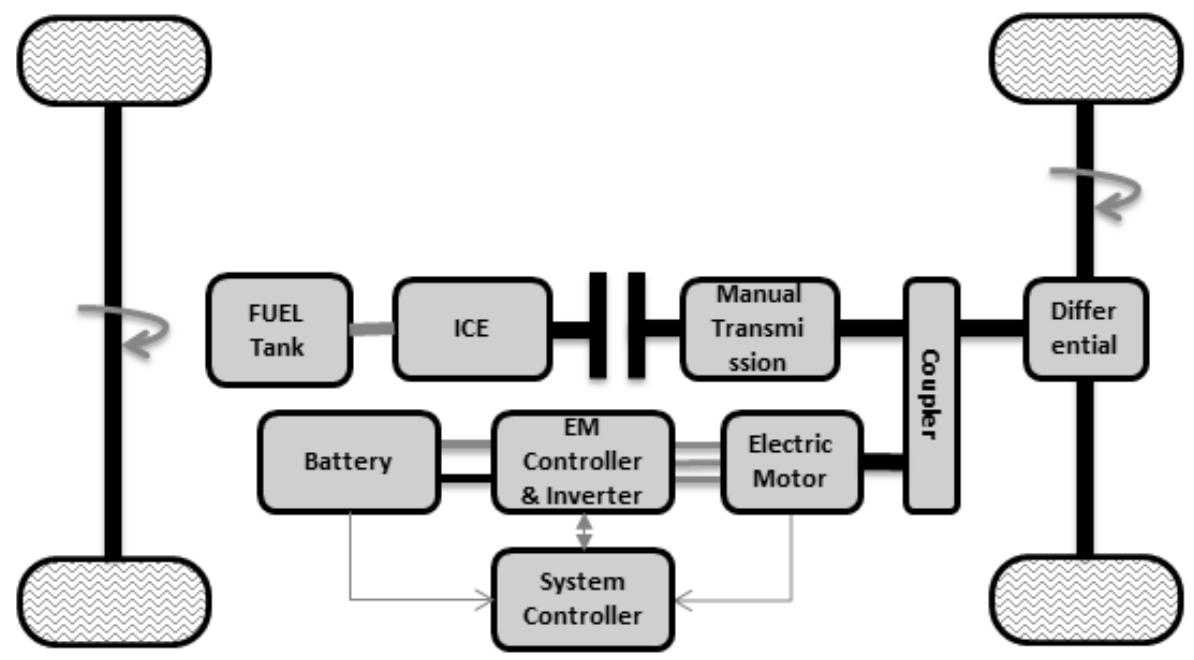

Figure 1. General Powertrain layout with hybridization.

The system dynamics and modelling constraints of this mild hybrid electric powertrain have been previously disclosed in papers by our research group, published in (18-20). In this prior research, a detailed multi-DOF system analysis was conducted. The equations governing the system were then indexed such that they could easily be integrated for computerized modelling. A brief discussion of shift quality and metrics was also presented, using the Vibration Dose Value (VDV) approach. This approach provides a metric for occupant comfort.

Drive cycle analyses were conducted to select the minimum practical electric motor and battery characteristics in order to enhance both performance and operating efficiency. The drive cycle analyses allowed identification of typical energy requirements, which were used to minimise the cost and size of the electric powertrain components. An extensive design study was conducted to select an appropriate electric motor. The motors studied had a very wide operating range and are a higher efficiency power source when compared to internal combustion engines (ICE), as they typically range from $65 \%$ to $95 \%$ round-trip efficiency $(21,22)$. The design study suggested that the most suitable EM for our low-cost HEV is a Brushless DC Motor (BLDC), with a rated continuous mechanical power output of $10 \mathrm{~kW}$ (30 kW peak), operating at $96 \mathrm{~V}$. Because of our intended use profile involves short pulses of high power for torque-filling, the peak mechanical power figure is as significant in our consideration as the continuous output. BLDC drive is widely used for EV and HEV applications (23-25). A $10 \mathrm{~kW}$ EM was found to satisfy most requirements for torque-fill in during gear change, and also has sufficient power to be able to be used for improving vehicle efficiencies under high demand or low engine efficiency conditions $(26,27)$. Although the selection of a $96 \mathrm{~V}$ operating voltage increases battery size and cost, it allows a significant size reduction in the motor, which is important for powertrain packaging. It is noted that current trends are toward a $48 \mathrm{~V}$ standard (28). However, many mild hybrid vehicles characterised by a low degree of hybridization operate on relatively higher voltages. These include Honda models fitted with Integrated Motor Assist, which operate on 144V (29). 
Despite the high voltage compared to current trends, the vehicle as presented is characterized by $14.2 \%$ degree of hybridization.

To perform a quantitative comparison analysis of electrical consumption, fuel economy, total lifetime (payback) cost and production cost, a schematic representation of the mild powertrain as illustrated in Figure 2 is modelled and simulated in Simscape environment of Matlab/Simulink. The vehicle selected is typical to the majority of passenger vehicles and is adapted as a mild HEV. It is categorised as a B-segment sedan $(30,31)$. Each component or system on the vehicle is sized appropriately using well-established analysis methods, in order to meet benchmark requirements. A model is also implemented for the driver, capturing unique, modifiable characteristics.

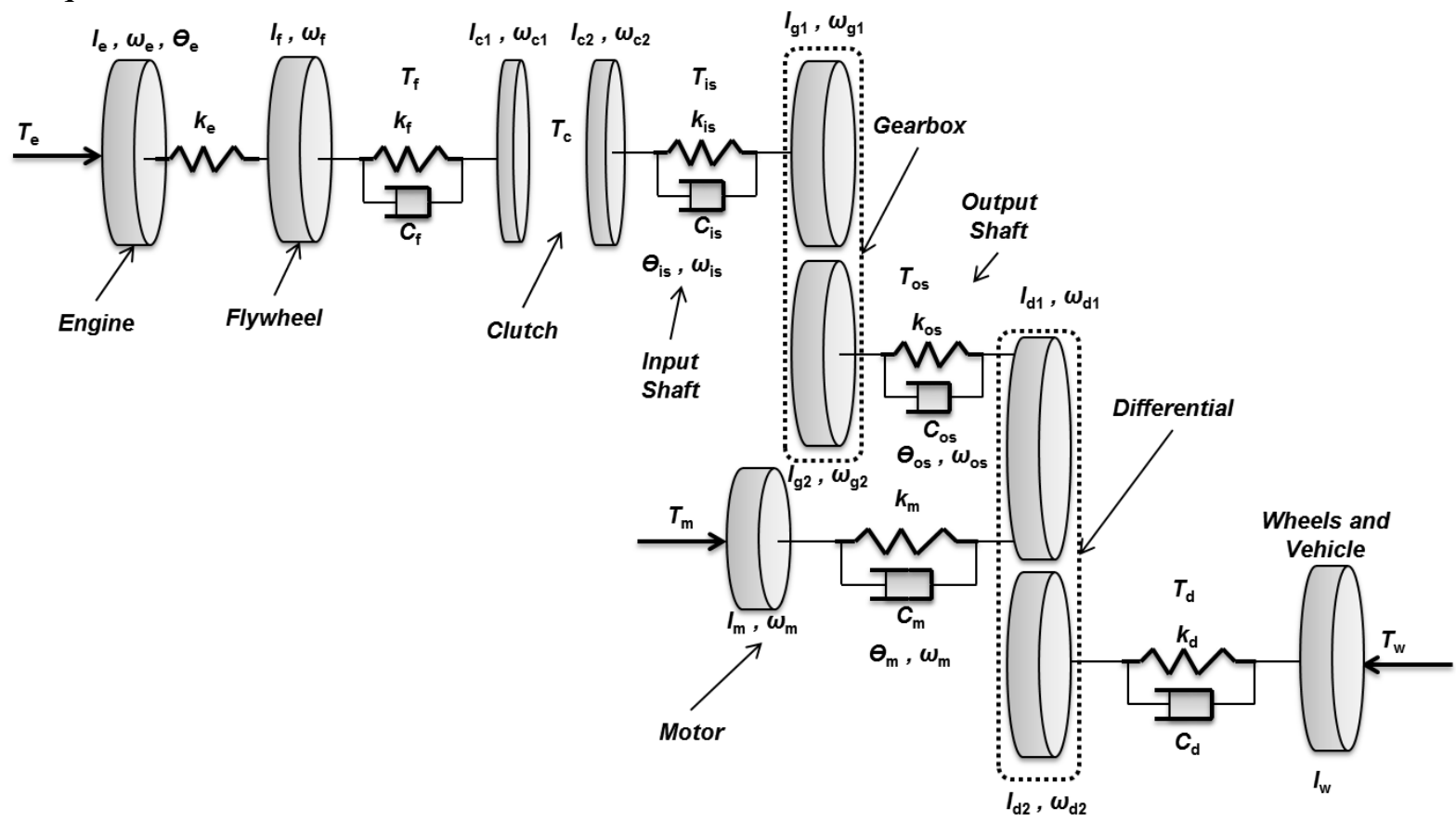

Figure 2. Kinematic diagram of a vehicle powertrain (32).

Table 1. Vehicle Global Specifications.

\begin{tabular}{|c|c|c|}
\hline Component & Parameter & SI Units \\
\hline \multirow{6}{*}{ Engine } & Type & Spark-Ignition \\
\hline & Maximum power & $70 \mathrm{~kW}$ \\
\hline & Maximum speed & $7000 \mathrm{rpm}$ \\
\hline & $\begin{array}{l}\text { Speed at maximum } \\
\text { power }\end{array}$ & $5000 \mathrm{rpm}$ \\
\hline & Cylinders & 4 \\
\hline & Idling speed & $800 \mathrm{rpm}$ \\
\hline \multirow{8}{*}{ Vehicle } & Drag coefficient & 0.4 \\
\hline & Frontal area & $3 \mathrm{~m}^{2}$ \\
\hline & CG to rear axle distance & $1.6 \mathrm{~m}$ \\
\hline & CG to front axle distance & $1.4 \mathrm{~m}$ \\
\hline & Tire rolling radius & $0.312 \mathrm{~m}$ \\
\hline & CG height & $0.5 \mathrm{~m}$ \\
\hline & $\begin{array}{l}\text { Rolling resistance } \\
\text { coefficient }\end{array}$ & 0.015 \\
\hline & Mass as hybrid & $1200 \mathrm{~kg}$ \\
\hline \multirow{2}{*}{ Clutch } & Type & Single Dry Clutch \\
\hline & Friction coefficient & 0.3 \\
\hline Gearbox & Type & $\begin{array}{c}\text { Manual, } 5 \text { forward } 1 \text { reverse, } \\
\text { fully synchronised }\end{array}$ \\
\hline
\end{tabular}




\begin{tabular}{|c|c|c|}
\hline \multirow{4}{*}{$\begin{array}{c}\text { Motor } \\
\text { MHEV } \\
\text { only) }\end{array}$} & Primary ratios & $3.581,2.022,1.4,1.03,0.94$ \\
\cline { 2 - 3 } & Final drive & 4.06 \\
\cline { 2 - 3 } & Model & $\begin{array}{c}\text { MARS ME0913 Brushless } \\
\text { DC 24 Pole }\end{array}$ \\
\cline { 2 - 3 } & Maximum power output & $96 \mathrm{~V}$ \\
\cline { 2 - 3 } Battery & Maximum torque & $10 \mathrm{~kW}$ \\
\hline & Type & $54 \mathrm{Nm}$ \\
\cline { 2 - 3 } & Capacity & $\mathrm{NiMH}$ \\
\cline { 2 - 3 } & Discharge/Charge rate & $1.2 \mathrm{kWh} / 12.5 \mathrm{Ah}$ \\
\hline
\end{tabular}

\subsection{Torque hole}

An opportunity to use the hybrid system to eliminate driving torque loss during gear shifting in the MT was realised. This opportunity has a commercial advantage in the intended markets due to its ability to maximise efficiency, drivability, and minimise cost as compared to other transmission technologies (CVT, DCT, AT). The drivability improvement acts as a commercial incentive to entice customers in these regions to pay a small, unavoidable premium for a hybrid vehicle. Because the cost of petrol in these regions is often quite cheap, minimised running cost was seen as only one of a variety of unique selling points of the proposed architecture. Further information on the development of the torque-hole elimination control can be found in (20).

\section{Energy Management strategy}

The EM provides or regenerates power, depending on vehicle operating conditions, which are monitored and controlled using an energy management controller (EMC). The energy management strategy plays is critical for managing the delivery of power from the engine and to and from the EM. Properly designed it increases driving performance and efficiency (33). The motor is controlled in four quadrants of operation, and together with the ICE can either drive the vehicle or be driven. A rule-based energy management strategy, described broadly by Figure 3, was deployed on the EMC. It depends on battery SOC and requested power, depending on various conditions the EM may generate power from either the ICE or vehicle kinetic energy. It may also be used to power the vehicle either independently or in conjunction with the engine. Because of the relatively small energy demands of the system as compared to a full hybrid, the regenerative braking function is vitally important, as it may be used to obtain a significant portion of these energy demands. The energy wasted in braking can easily exceed 50\% during daily peak-hour driving, especially in metropolises (34). By utilising the EM extensively under all favourable conditions, system benefits can be maximised. Energy storage and power requirements are determined by considering the demands placed by motive assistance, and the energy capture possible through regenerative braking and ICE-generator.

There are six rule-based operating modes, which may be summarised as follows;

1. Regenerative Braking: The EM functions as a generator when the vehicle is braking, and SOC is less than maximum. The braking torque of the generator determines the maximum and minimum electric brake force applied to the wheels.

2. EM as a generator: The EM functions as a generator when the vehicle is accelerating, SOC is low, and engine load point without generator load is inefficient. 
3. Torque Assist: The EM is driven in motoring mode when SOC is not low and delivers torque that complements the engine based on the requirement, especially during acceleration conditions.

4. Electric-only Mode: Under certain low-speed light-load conditions and when SOC is high (>80\% Depth of Discharge, DoD), the EM may supply all of the motive force required. This mode is developed for implementation with an AMT.

5. Torque-hole Mode: During gear change and when SOC is not low, the EM provides a tractive force that is synchronised to the gear change. Low SOC is defined as $<40 \%$ DoD.

6. Idle Mode: In this mode, the EM runs in idle condition. That is, it does not act as a generator nor does it at as a motor. This mode is often observed when the battery is fully charged, and the vehicle is cruising at high speeds and avoids loading the engine unnecessarily.

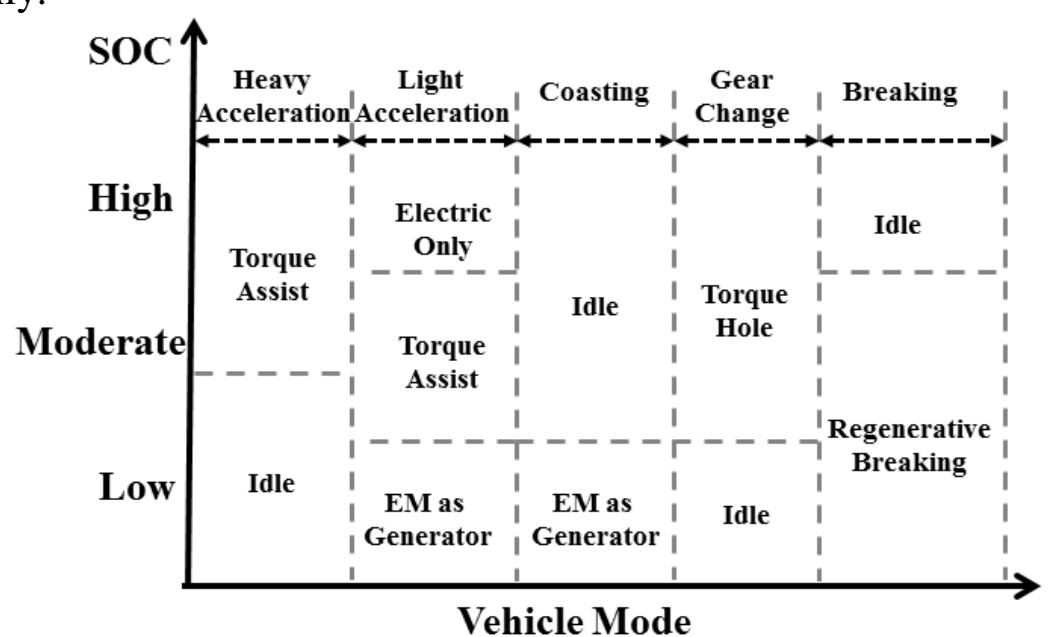

Figure 3. EM modes of operation

The implementation of an appropriately configured battery pack improves the suitability of the system in recovering braking energy under saturated load conditions (i.e. high speed or high braking demand). By sizing the battery for peak charging as well as peak discharging demands, the back EMF generated by the motor may be efficiently harnessed to charge the pack if battery SOC permits. The SOC is further defined in the following section.

\section{Simulation Analysis}

The physical vehicle parameters on which the simulation is based were taken from a 1990 model Mazda MX-5 (Miata) (35). This vehicle model was selected as its characteristics (notwithstanding the convertible body) are highly representative of many vehicles being sold new in developing regions. It uses a low-tech 4-cylinder with power output and other physical characteristics typical of most B- and C-segment vehicles, and shares similar weight with these vehicles. In addition to this, the lightweight and simple body and rear drive powertrain, as well as the easy and cheap availability of parts in Australia made this vehicle choice appropriate as a basis for the later development of the physical prototype. It was expected to be substantially simpler to modify the rear-drive powertrain and open-top body for hybridization than would be a more typical B/C-segment front-drive hatchback, which is the only other vehicle configuration widely available in Australia that approaches the desired characteristics. 


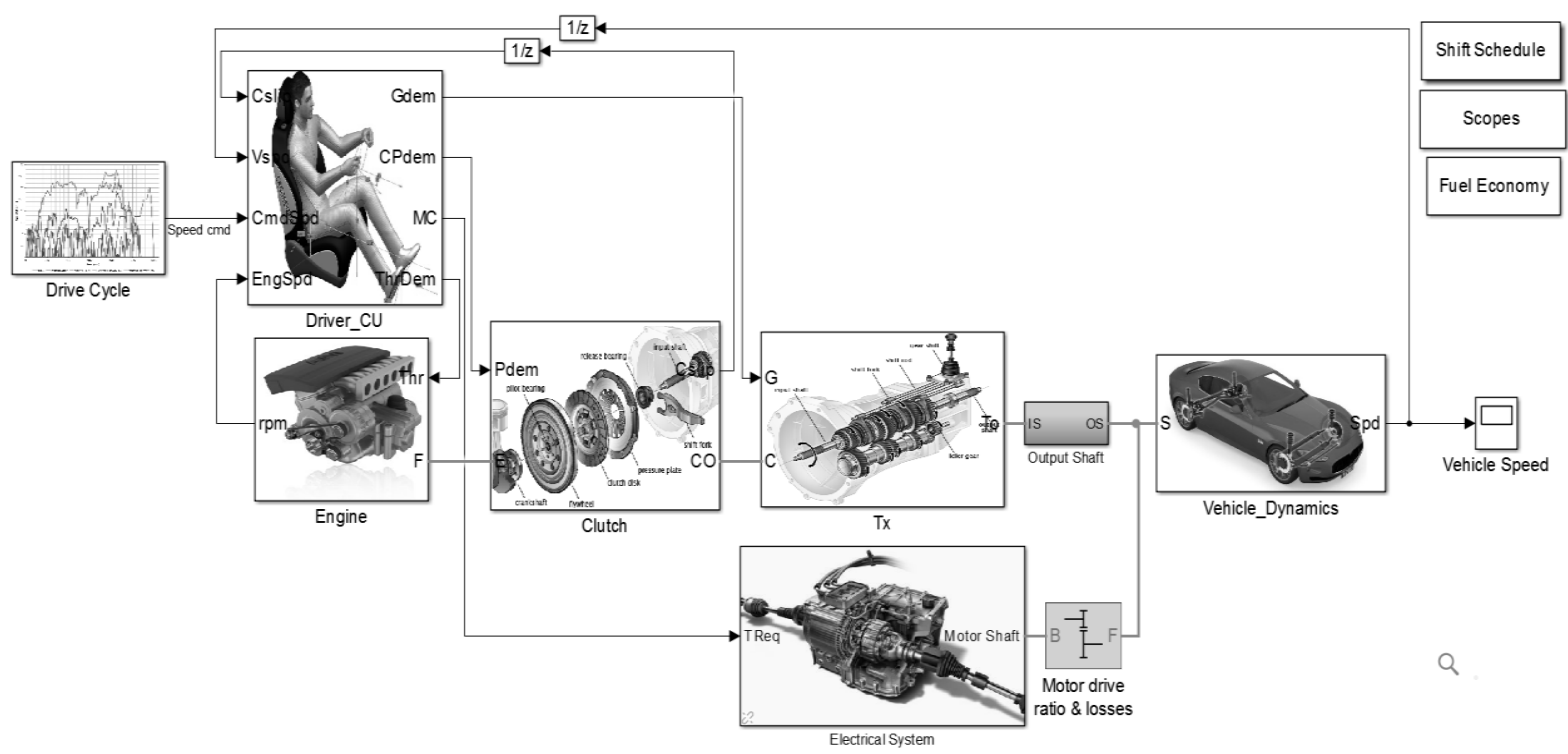

Figure 4. A high-level view of the powertrain of the mild HEV model in Simulink.

\subsection{Modelling environment}

A complete vehicle model, including physical and control components, was developed in Simscape using the SimDriveline and Simscape toolboxes. Given the complexity of the model, solvers were implemented and configured to optimise ensure both simulation accuracy without compromising the speed of these simulations (36). The simulation uses the velocity profile of the assigned driving schedule as an input. From this, torque and power demands are generated and distributed by component characteristics and selected operating strategies. Figure 4 presents the top level block diagram of the vehicle model. It is a forwardfacing modelling strategy. The force-generating systems such as tires, powertrain, brakes, suspension, and aerodynamics are taken into account in the model. The driver is modelled using a PID controller, with adaptations to determine acceleration/braking requirements. Gear change is determined according to a two-dimensional shift schedule. Many typical city driving cycles can be simulated in the 'Driver' unit to yield more realistic simulation results, as discussed in (20).

\subsection{Vehicle torque model}

The vehicle block represents the overall vehicle body and its associated characteristics such as mass distribution, aerodynamic drag and longitudinal motion. This model is integrated with differential and tyre models. With the tyre model including rotating inertia, rolling resistance and contact models with the road $(37,38)$. Again these are implemented from the Simscape toolbox in Matlab.

\subsection{Motor model}

To simplify the system model, a DC equivalent motor model is used to represent the electric prime mover. This simplification reduces the three phase permanent magnet motor to a simple two degree of freedom model and allows direct control of input voltage without consideration of power electronics for these simulations. The complexity of simulating power electronics is eliminated, and the direct voltage control of the motor is therefore possible. Figure 5 shows the torque and power curves of the motor. System parameters are taken from available equipment used in previous experiments (39). 

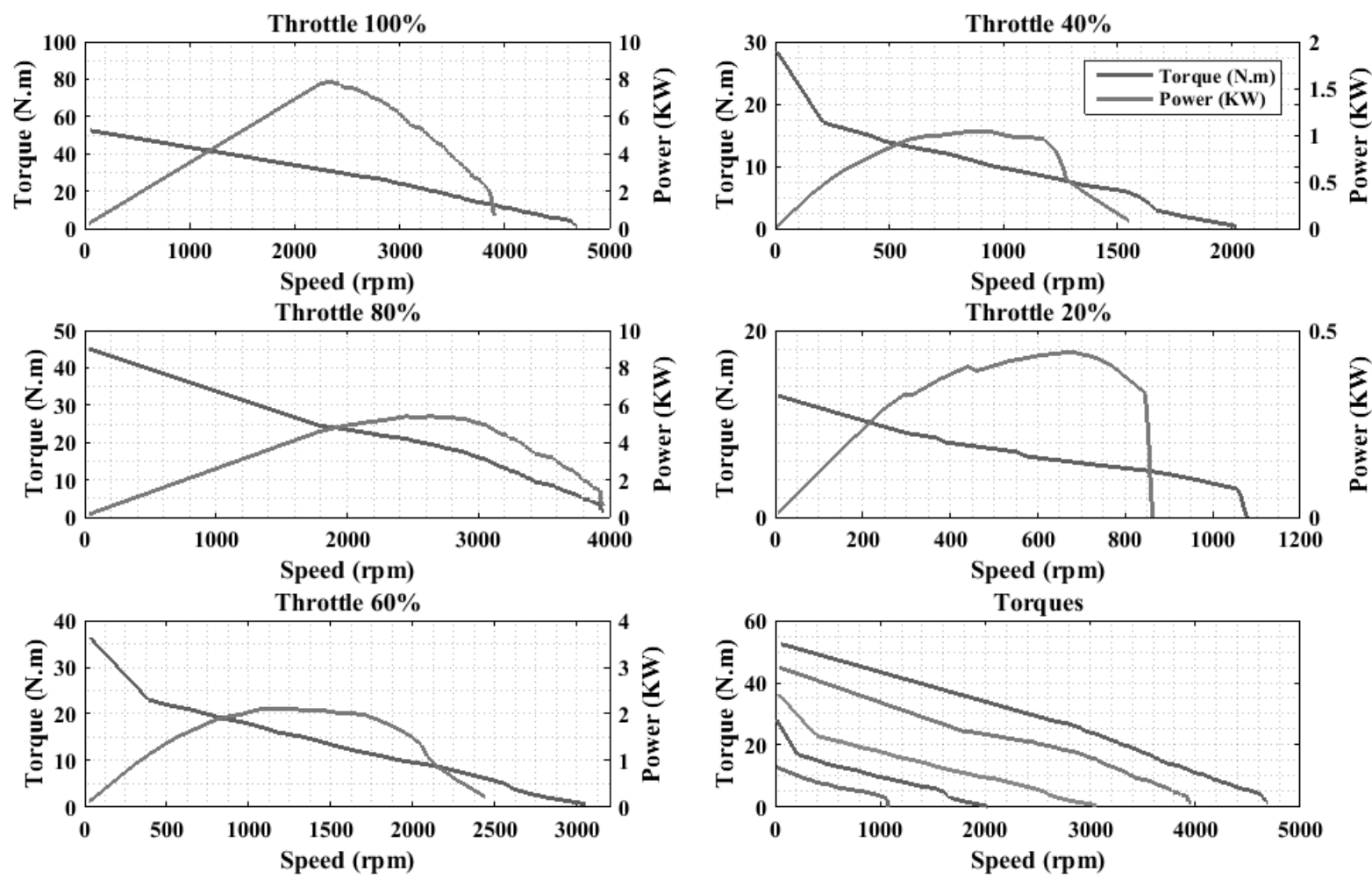

Figure 5. Torque and Power vs. Speed of the motor at different throttles (40).

\subsection{Engine model}

The physical simulation models of engine and control were established within the Simscape environment. Because the engine model only needs to output a desired torque and speed in response to a given throttle command, the "Generic Engine" component in the SimDriveline package offers sufficient functionality for our needs. This development strategy has been successfully used in the prior literature $(41,42)$. Figure 6 shows the engine map and the maximum torque line of the engine.

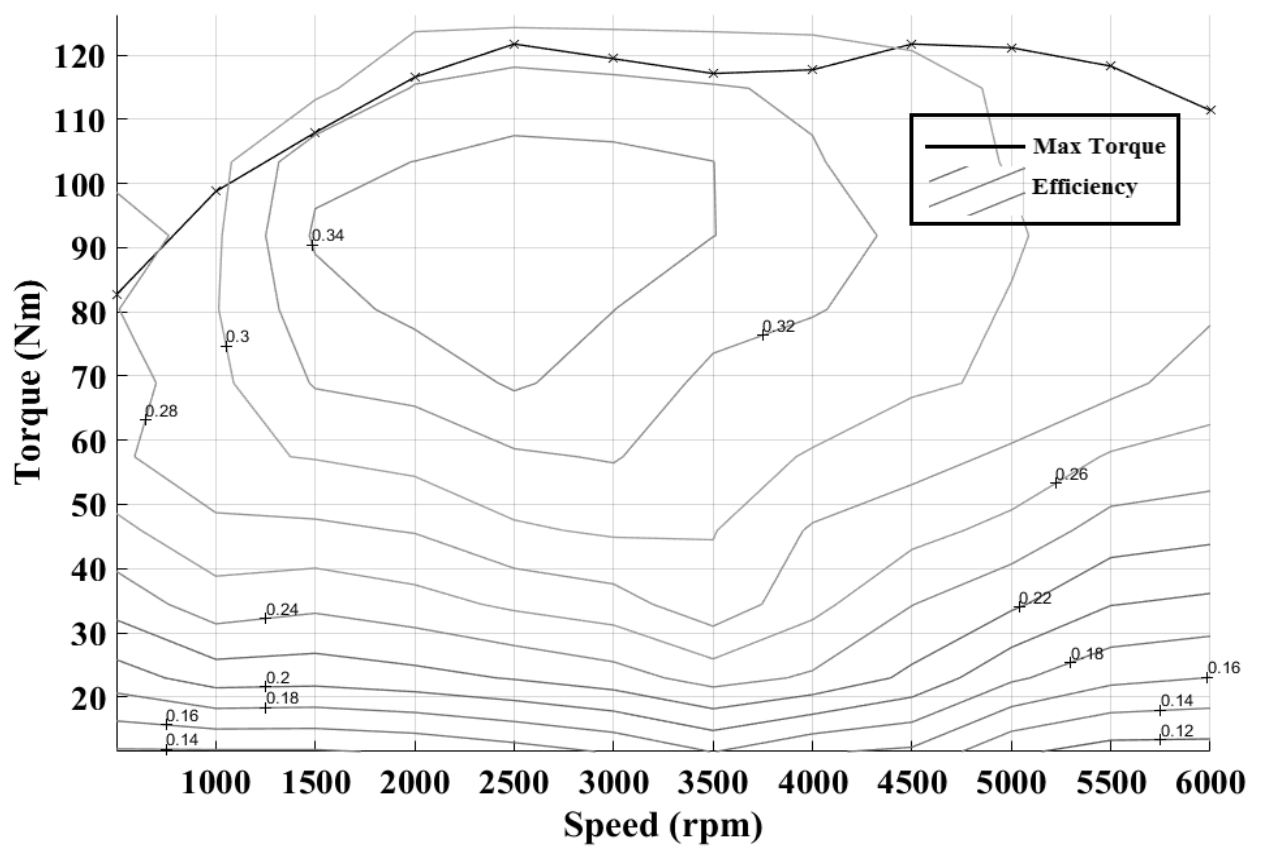

Figure 6. Engine map. 


\subsection{Transmission actuation and Driver control}

A Driver and vehicle control unit is used to provide engine and the electric machine (EM) with required torque signals. The driver is modelled as PI controller designed to calculate the required traction torque for tracking a speed reference. The negative part of the control signal generates a negative torque load to brake the vehicle with mechanical and regenerative braking, while positive part generates positive traction torque. The traction torque is proportional to the maximum available torque and the throttle position. The control parameters and modelling constraints of this model have been previously disclosed in a paper by our research group, published in (43). As the system is based on a conventional manual transmission, the actuation process is relatively simple. It is divided into four stages:

A. Release throttle and open primary clutch

B. Disengage current gear

C. Select and engage target gear

D. Close primary clutch and restore engine power.

A detailed simulation based study of the transient behaviour during gear change can be found in (20). These results demonstrated a reduced shifting time and improved shifting performance in terms of transient vibrations for proposed mild hybrid vehicle. For the purpose of this paper linkages and actuators have been replaced with ideal force inputs. This simplifies the modelling process without losing the desired characteristics of the powertrain.

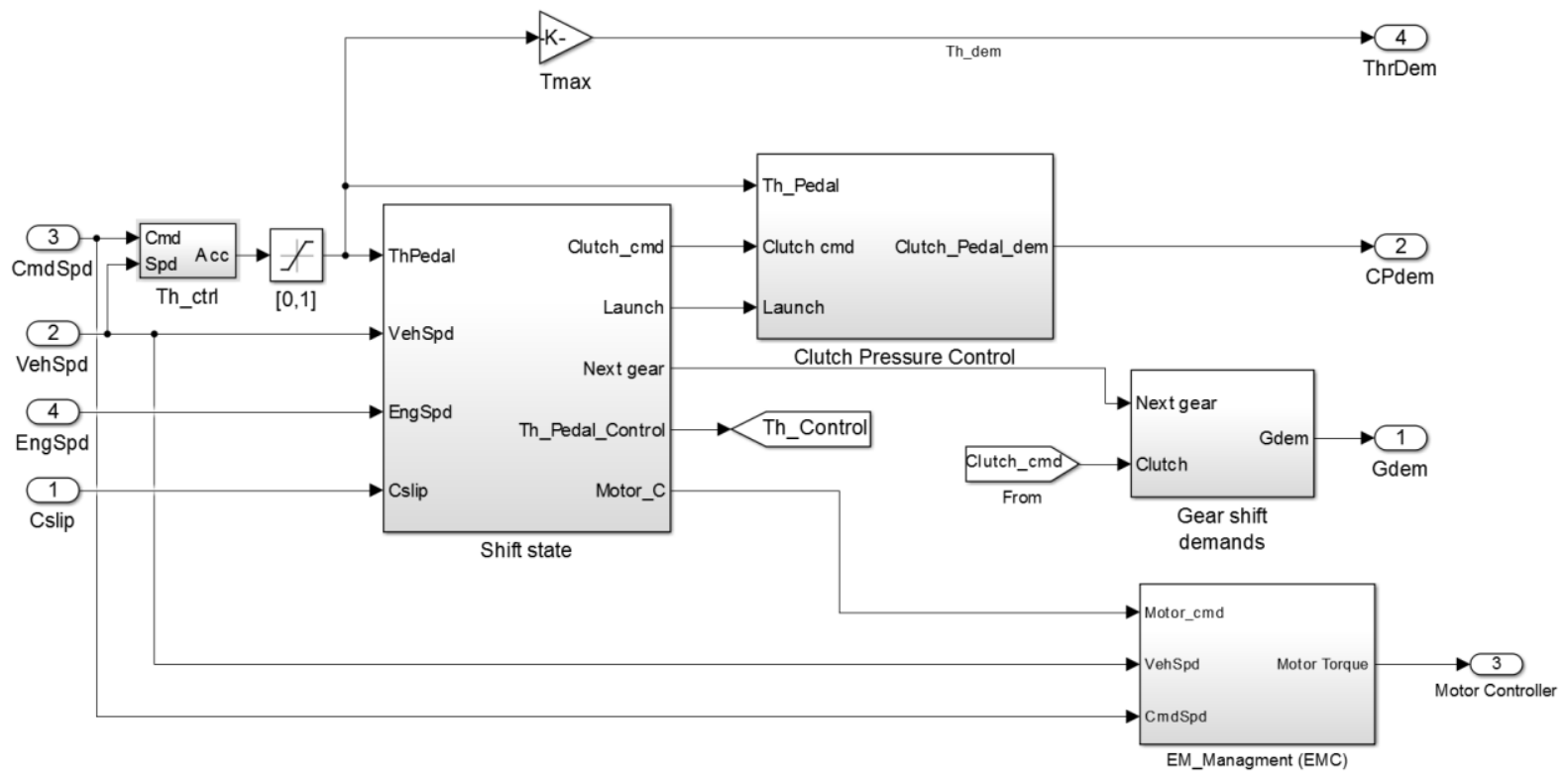

Figure 7. System-level representation of a driver and controller.

\subsection{Drive cycles}

The drive cycles used for the simulation are New York City Drive Cycle (NYCC), Urban Dynamometer Drive Schedule (UDDS) and New European Drive Cycle (NEDC). These are illustrated in Figure 8. Table 2 shows some characteristic parameters of the selected drive cycles, according to these parameters the cycles can be classified into different driving patterns $(44,45)$. The NEDC was utilised primarily to provide a better comparison with the literature, as it has been adopted as a standard in many developed regions. However, the UDDS and NYCC were selected owing to their low average speed and frequent stops, which are more representative of the typical urban driving conditions that were being replicated. The NYCC has an average speed of less than $20 \mathrm{~km} / \mathrm{h}$, but speed fluctuation is high. It is also characterised by frequent stops, representing the high levels of heavy traffic that would be seen in developing metropolises. In comparison, the NEDC average speed and speed fluctuation are both moderate, representing typical driving conditions in a suburban area. The 
cycle is characterised by fewer idle times and includes high-speed cruising. A highway cycle is not representative of real world driving in our target market and is not considered useful to this study. This is validated by prior literature, e.g., $(46,47)$, which establishes that the percentage improvement in fuel economy by adopting mild hybrid configurations for highway cycles is significantly less than for city driving.

Table 2. Characteristic parameters of different driving cycles.

\begin{tabular}{|c|c|c|c|c|c|c|c|c|c|}
\hline & Distance & Time & $\begin{array}{c}\text { Idle } \\
\text { Time }\end{array}$ & $\begin{array}{c}\text { Max } \\
\text { Speed }\end{array}$ & $\begin{array}{c}\text { Avg } \\
\text { Speed }\end{array}$ & $\begin{array}{c}\text { Avg } \\
\text { Acc }\end{array}$ & $\begin{array}{c}\text { Avg } \\
\text { Dec }\end{array}$ & $\begin{array}{c}\text { Max } \\
\text { Acc }\end{array}$ & $\begin{array}{c}\text { Max } \\
\text { Dec }\end{array}$ \\
\hline NEDC & 10.8 & 1184 & 298 & 120 & 33.21 & 0.54 & -0.79 & 1.06 & -1.39 \\
\hline UDDS & 11.9 & 1369 & 259 & 91.25 & 31.51 & 0.5 & -0.58 & 1.48 & -1.48 \\
\hline NYCC & 1.87 & 598 & 210 & 44.58 & 11.41 & 0.62 & -0.61 & 2.68 & -2.64 \\
\hline
\end{tabular}
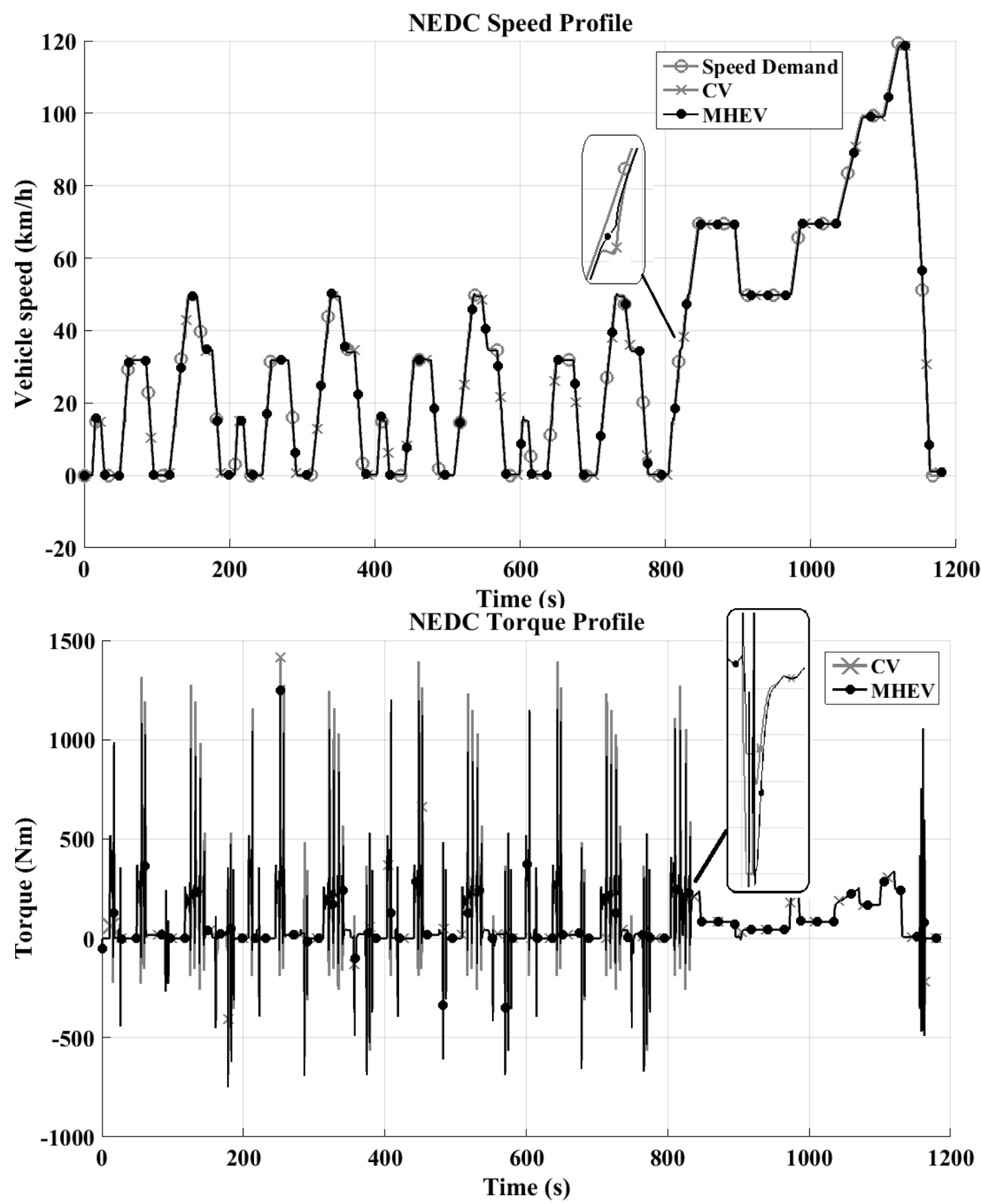

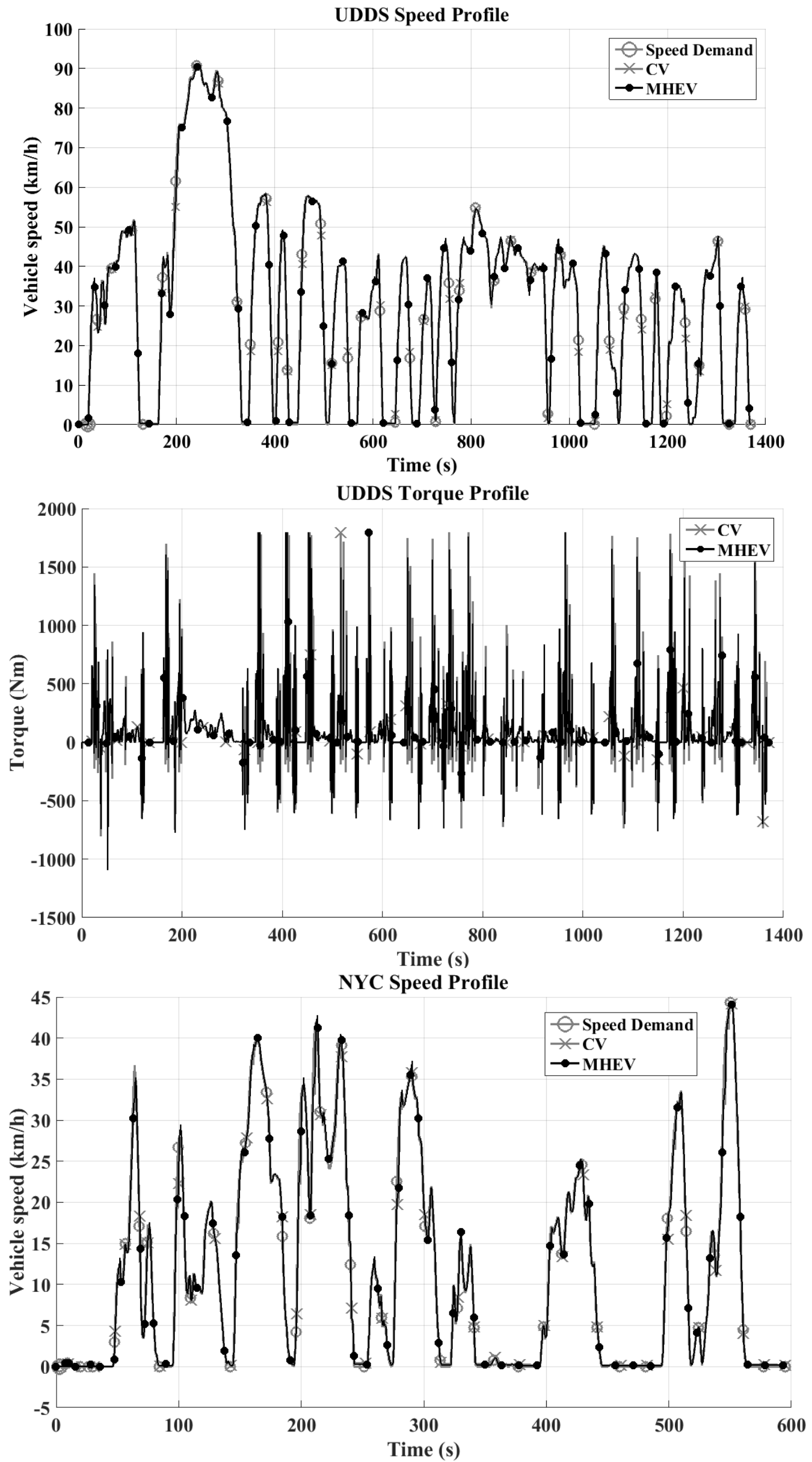


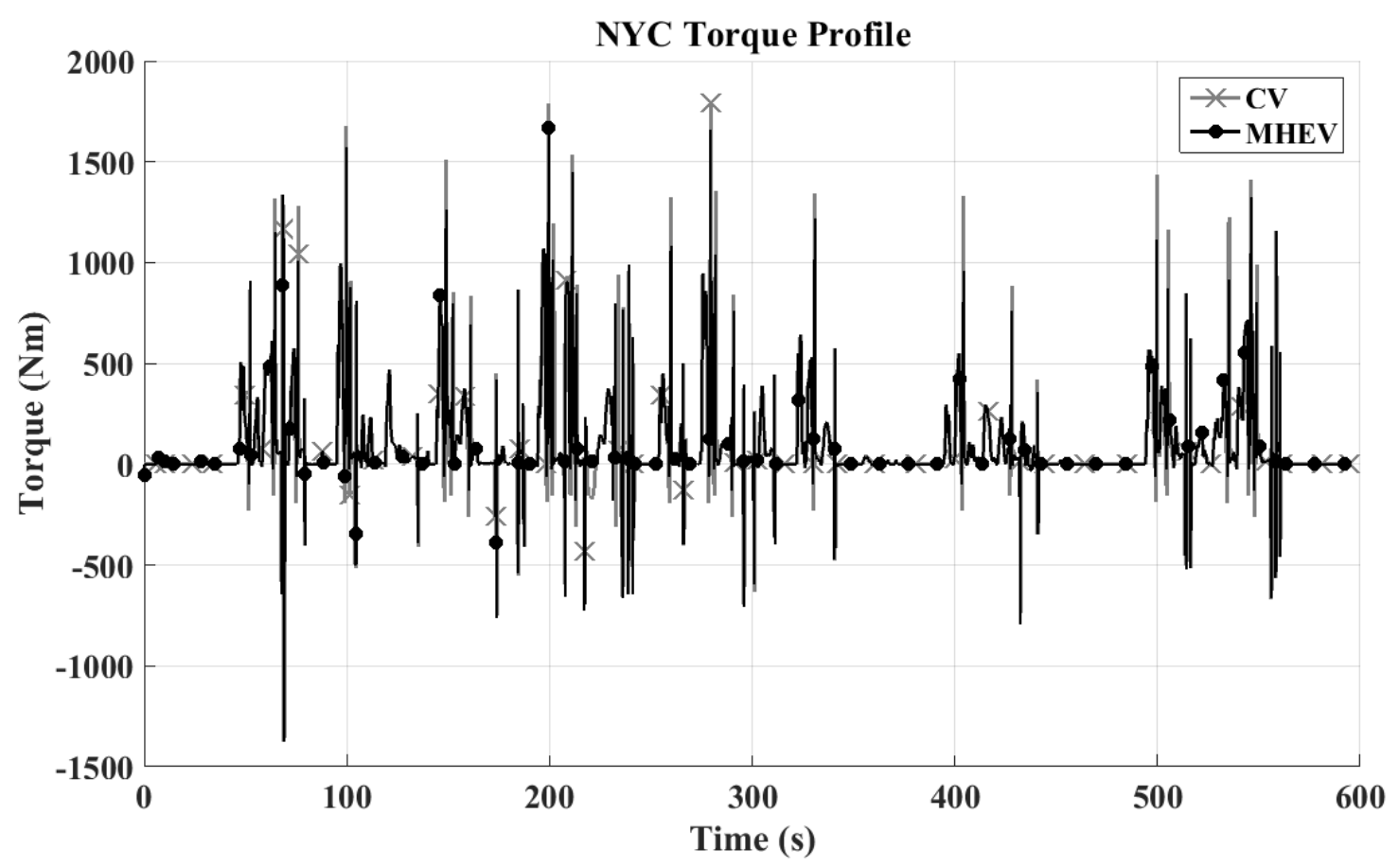

Figure 8. Speed and Torque profile for the NEDC, UDDS and NYCC.

\subsection{State of charge}

A number of alternative forms of energy storage are considered for HEVs, i.e. batteries, supercapacitors hydraulics, or flywheels. To be cost effective, the system herein uses batteries. The sizing of the energy storage can be investigated using power flow needs, regenerative braking capacity, and cycle life. The motor power demand is calculated based on benchmarking simulations of the vehicle and physical characteristics. For energy management purposes, the SOC is used to judge the most suitable driving mode for the vehicle and provides information as to the residual power available (31). Note also that the capacity and battery efficiency temperature are dependent. SOC is calculated as:

$$
\begin{aligned}
& \text { SOC }=\frac{(\text { Max_Capacity }- \text { Ah_used })}{\text { Max_Capacity }} \\
& \text { SOC }=\left(1-\frac{\int_{0}^{\text {time }(s)} \operatorname{Current}(A)}{3600 \times \text { Battery Maximum Capacity }(A h)}\right) \times 100 \%
\end{aligned}
$$

When running the cycle simulations, if the SOC value drops at the completion of a driving cycle (i.e., there is a net discharge), then the magnitude of the discharge must be taken into account when calculating fuel economy. The controller in Figure 3 prevents the SOC of the battery from dipping under the "low" threshold, which can be modified in the model. By setting the threshold and running the simulation iteratively, the simulation allows us to arrive at an optimal battery size. The SOC variations under the NYCC, NEDC, and UDDS drive cycles are presented in Figure 9. The simulations are conducted with an initial SOC $=0.9$ and 0.5 . In both simulations, 0.5 is set as the low threshold; the results show the proposed control strategy is capable of maintaining the balance of SOC and illustrates the SOC accumulated deviation at the end of each cycle. 

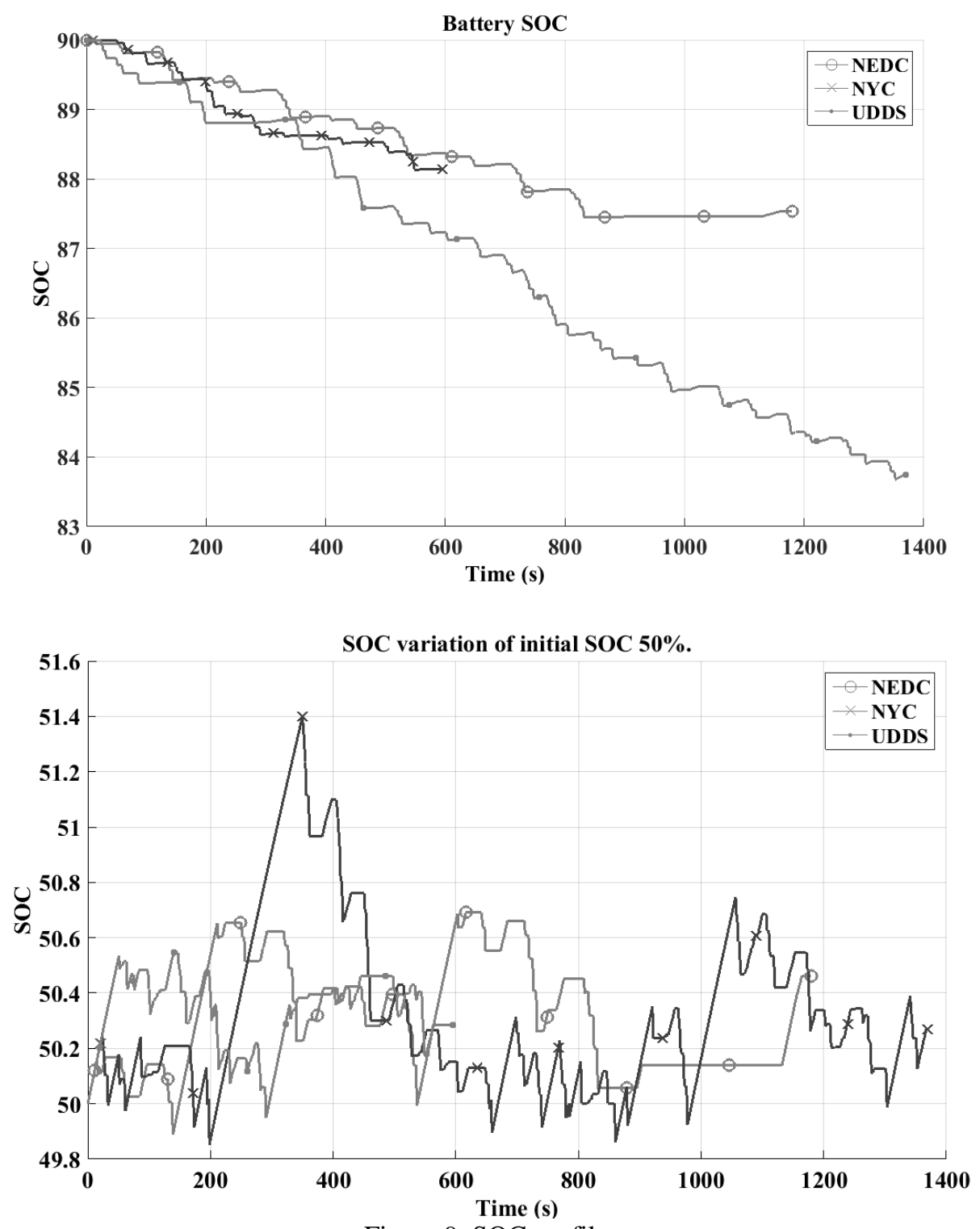

Figure 9. SOC profile.

\section{Fuel Economy Benefit}

In this section, we aim to estimate the energy usage (fuel and electrical) for both the conventional and the hybrid vehicle configurations. To do this, the conventional vehicle on which the hybrid is based (Mazda MX-5 MY90) is modelled as the base vehicle scenario. Its model is run through simulations that are validated using legislated drive cycles. These drive cycles focus on urban environment simulation, where fuel consumption can often be up to $50 \%$ higher than free-flowing (highway) environments. These environments represent the greatest possibility of improvement $(48,49)$. In the second step, the electric side of the powertrain is added to the baseline vehicle model, and the simulation is run otherwise identically. This step provides a second set of results which can be benchmarked against the baseline.

\subsection{Conventional Vehicle Model energy usage}

Computer modelling and simulation can reduce the expense and length of the design cycle of hybrid vehicles prior to the prototyping stage. A number of different software platforms have been developed to enable the accurate simulation of HEVs. These software solutions are 
either forward-looking in nature or backward-looking. In the forward-looking approach, the driver module provides the input to the model, which reacts to the driver commands to follow a defined speed profile. In contrast, the backwards-looking approach uses the vehicle speed as an input to define the parameters that are required to meet the input demand. To ensure accuracy and validity of comparison in regards to the fuel efficiency study in this work, we adopted the ADVISOR modelling tool $(50,51)$, which has been adopted by many researchers previously. ADVISOR uses a backward-looking approach to provide realistic fuel economy results over a wide range of vehicles $(52,53)$. Instantaneous fuel consumption is based on a three-dimensional lookup table defined by engine operating point (speed and torque). Integrating instantaneous fuel consumption provides a fuel consumption figure. Key vehicle specifications were inserted into the model based on values shown in Table 1. The instantaneous fuel lookup table is a modified base map prebuilt into ADVISOR. To accelerate the development process for the ADVISOR model, existing components within the ADVISOR component library which approach the requirements of our vehicle model. These components are then modified as required to meet the specifications available with regards to fuel economy, power, and tailpipe emissions.

Table 3 presents the cumulative cycle fuel consumption for each simulated cycle. The figures are sufficiently close to the reported consumption by ADVISOR to indicate that the model is accurate for the purpose of the financial analysis presented herein.

Table 3. The reported consumption $\mathrm{L} / 100 \mathrm{~km}$.

\begin{tabular}{|c|c|c|c|}
\hline & NEDC & UDDS & NYCC \\
\hline ADVISOR Model & 8 & 8.1 & 18 \\
\hline Simulation Model & 7.84 & 8.1 & 17.8 \\
\hline
\end{tabular}

\subsection{Analysis of fuel economy and electricity consumption}

For both the hybrid and the conventional vehicle configurations presented above, energy consumption (petrol and electricity) can be evaluated. For comparison, the energy consumption is calculated over three legislative cycles, NEDC, UDDS and NYCC, which are all urban cycles. The urban cycles are deliberately selected because they represent well the typical conditions in the densely populated metropolises of developing regions. The stop-start traffic flow in these cities contributes substantially to fuel use (54). The purpose of using multiple cycles is to provide a more diverse set of driving conditions, reducing bias of the results to a particular drive cycle. Fuel economy was calculated for both the baseline and the hybrid vehicle; the results are summarised in Table 5. Substantial differences in fuel economy are observed when comparing different drive cycles. As expected, a saving of approximately 3 - 8\% fuel consumption represents a consistent improvement in fuel economy over the conventional powertrain. While the quantum of fuel saving is dependent on the drive cycle; the trend clearly shows an improvement.

To compensate for the change in SOC over once cycle, see Capacity in Table 4, an adjustment to the fuel consumed is made in accordance with (55). In (55) an equivalent fuel consumption is required to evaluate the equivalent economy of conventional, hybrid and electric vehicles. This type of regulation provides equivalency between various vehicle types so as to standardise the fuel consumption rates. The conversion of energy battery energy to energy in gasoline (petrol) is $34.2 \mathrm{MJ} / \mathrm{L}$ (56). It is adopted for this research paper. Therefore we can compensate for energy consumption in the battery and directly compare fuel savings between both vehicles. 
Table 4. Comparison chart for all vehicles tested Fuel and electricity consumption of the modelled vehicles.

\begin{tabular}{|c|c|c|c|c|c|c|}
\hline Drive Cycle & \multicolumn{2}{|c|}{ NEDC } & \multicolumn{2}{c|}{ UDDS } & \multicolumn{2}{c|}{ NYCC } \\
\hline Drivetrain & CV & MHEV & CV & MHEV & CV & MHEV \\
\hline $\begin{array}{c}\text { Fuel Economy } \\
(\mathrm{L} / 100 \mathrm{~km})\end{array}$ & 7.841 & 7.645 & 8.158 & 7.485 & 17.6 & 16.98 \\
\hline $\begin{array}{c}\text { Fuel Consumption } \\
\text { L }\end{array}$ & 0.849 & 0.825 & 0.969 & 0.885 & 0.328 & 0.316 \\
\hline $\begin{array}{c}\text { Capacity } \\
\text { Ah }\end{array}$ & - & 0.9 & - & 2 & - & 0.7 \\
\hline
\end{tabular}

Table 5. Fuel Economics for conventional and Mild HEV.

\begin{tabular}{|c|c|c|c|c|c|c|c|c|}
\hline \multirow{3}{*}{$\begin{array}{l}\text { Drive } \\
\text { cycle }\end{array}$} & \multicolumn{3}{|c|}{ Motor } & \multicolumn{4}{|c|}{ Fuel Economy (L/100 km) } & \multirow{3}{*}{$\begin{array}{c}\text { Fuel } \\
\text { saving }(\%)\end{array}$} \\
\hline & \multicolumn{6}{|c|}{ MHEV } & \multirow[t]{2}{*}{$\mathrm{CV}$} & \\
\hline & $\mathrm{Ah}$ & $\mathrm{kW} \cdot \mathrm{h}$ & Equivalent MJ & Motor & ICE & Total & & \\
\hline NEDC & 0.9 & 0.0864 & 0.31104 & 0.00909 & 7.645 & 7.654 & 7.841 & 2.38 \\
\hline UDDS & 2 & 0.192 & 0.69120 & 0.02021 & 7.485 & 7.505 & 8.158 & 8.1 \\
\hline NYCC & 0.7 & 0.0672 & 0.24192 & 0.00707 & 16.98 & 16.987 & 17.6 & 3.48 \\
\hline
\end{tabular}

From the simulation output, it can be concluded that the mild HEV powertrain plays a noteworthy role in enhancing fuel economy. The requirements for motor capacity and torque under acceleration are much higher than that for other requirements (e.g., cruising). In other words, most of the motor capacity is wasted in the daily-use. Therefore, a design trade-off has to be made between acceleration time, energy consumption, and motor cost.

\subsubsection{Physical Performance Benchmarking and Torque-Hole Elimination}

To benchmark vehicle performance, a $0-100 \mathrm{~km} / \mathrm{h}$ test was adapted from the first section of the Rural Drive Cycle (RDC, Figure 10). This test is modified to keep shift points at the optimal engine speed for fuel economy, and both the baseline and the hybrid vehicle were tested. The primary functionality of this HEV arrangement, torque-fill system, is not the dominating factor for improving fuel economy. It is, however, a side benefit. The use of regenerated electrical power to perform shifts is expected to have an impact on fuel economy as the gear shift performance is improved and less energy wasted during these events. To demonstrate this the torque fill-in configuration is compared to a conventional ICE powertrain (shown in Figure 10). Results are presented in Table 6. results are presented in Table 6. A $4.2 \%$ improvement in fuel economy is demonstrated through these simulations over the conventional vehicle, and the overall acceleration time from a stand still is reduced by about $2.5 \mathrm{Sec}$ when using torque fill-in. This is a result of the continual delivery of tractive load to the road during gear shift by the electric motor drive, note that deceleration during gear shifts is significantly reduced.

Table 6. Comparison chart for configurations tested through the acceleration event $0-100 \mathrm{~km} / \mathrm{h}$

\begin{tabular}{|c|c|c|}
\hline Vehicle Model & $\begin{array}{c}\text { Distance Travelled } \\
\mathrm{km} / \mathrm{L}\end{array}$ & $\begin{array}{c}\text { Fuel Economy } \\
\mathrm{L} / 100 \mathrm{~km}\end{array}$ \\
\hline Conventional & 12.98 & 7.702 \\
\hline Mild HEV & 13.54 & 7.381 \\
\hline
\end{tabular}



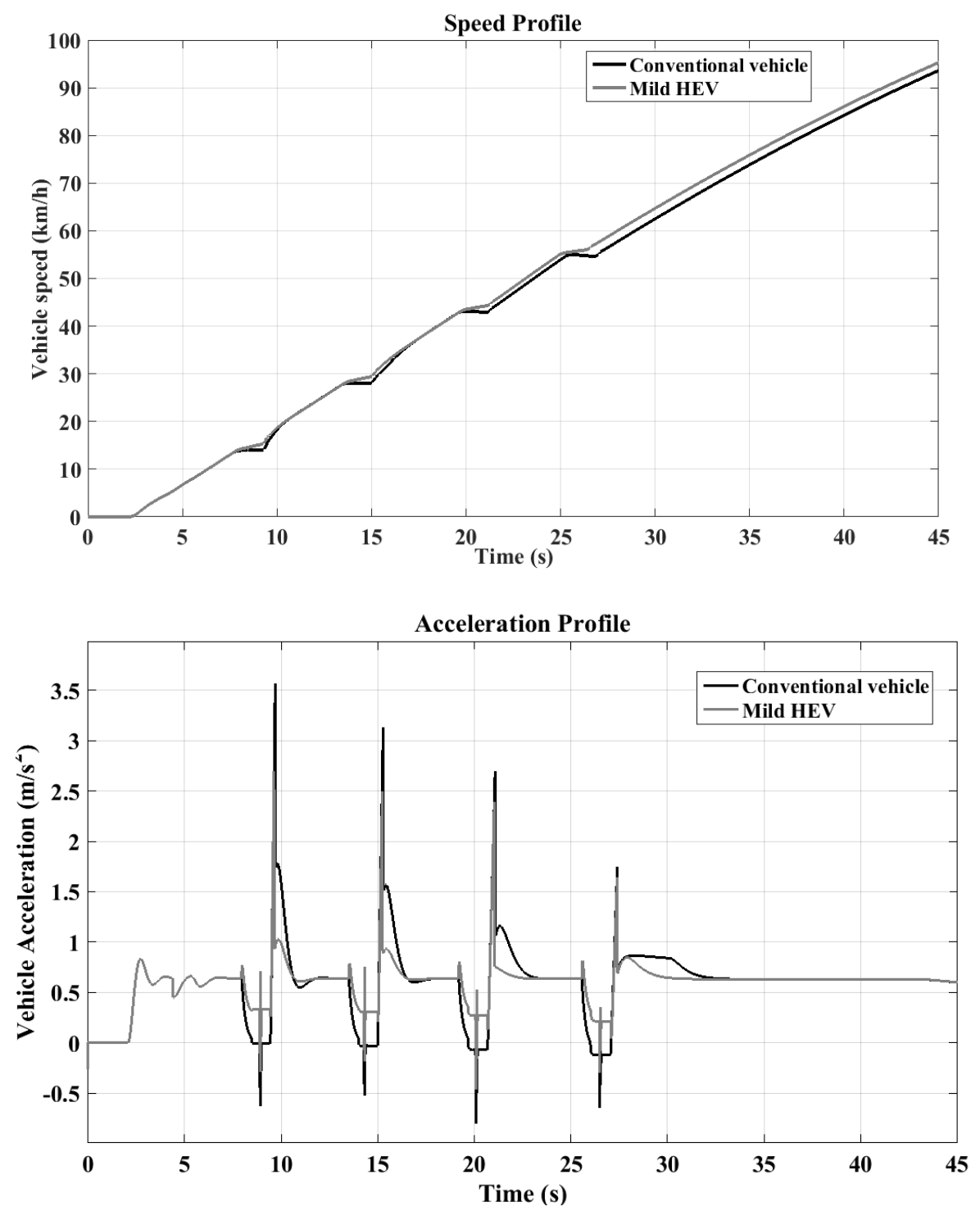

Figure 10. Benchmarking test - vehicle speed and acceleration profile.

\subsection{Direct emissions}

It is predicted $(57,58)$ that in the next decade mild hybrid electric vehicles will become a leading automotive growth sector. Electrified vehicles offer the promise of reduced emissions when compared with conventional vehicles, due to the more efficient use of combustion power and resultant emissions. Emission rates were calculated in our model as an average of the values measured over each drive cycle and measurement set. They were normalised by fuel flow rate. The fuel ratio is a crucial factor that has a dominant effect on emissions characteristics of an SI engine (59). Exhaust gas components measured were nitrogen oxides (NOx), carbon monoxide (CO) and unburned hydrocarbons (HC) $(60,61)$. Simulations of the vehicle configurations over the drive cycles resulted in vehicle performance as given in Table 7. There is a clear trend describing Mild HEV pollutant emissions which are lower than those of the conventional vehicle. Of note is the mild hybrid vehicle's performance in the reduction of tailpipe $\mathrm{HC}$ emissions compared to the conventional vehicle, which indicates that the engine is operating more efficiently and achieving complete combustion more frequently. This result correlates well with the results achieved in Table 4. 
Table 7. GHG Emissions for conventional and Mild HEV.

\begin{tabular}{|c|c|c|c|c|c|c|c|c|c|}
\hline \multirow{2}{*}{ Vehicle } & \multicolumn{9}{|c|}{$\begin{array}{c}\text { Emissions } \\
\text { (grams/km) }\end{array}$} \\
\cline { 2 - 11 } & \multicolumn{3}{|c|}{ NEDC } & \multicolumn{3}{c|}{ UDDS } & \multicolumn{3}{c|}{ NYCC } \\
\cline { 2 - 10 } & $\mathrm{HC}$ & $\mathrm{CO}$ & $\mathrm{NO}_{\mathrm{x}}$ & $\mathrm{HC}$ & $\mathrm{CO}$ & $\mathrm{NO}_{\mathrm{x}}$ & $\mathrm{HC}$ & $\mathrm{CO}$ & $\mathrm{NO}_{\mathrm{x}}$ \\
\hline $\begin{array}{c}\text { Conventional } \\
\text { drivetrain }\end{array}$ & 0.565 & 1.62 & 0.729 & 0.54 & 1.637 & 0.718 & 2.966 & 9.558 & 3.758 \\
\hline $\begin{array}{c}\text { Mild Hybrid } \\
\text { drivetrain }\end{array}$ & 0.518 & 1.54 & 0.716 & 0.503 & 1.57 & 0.693 & 2.576 & 8.249 & 3.223 \\
\hline $\begin{array}{c}\text { Improvement } \\
(\%)\end{array}$ & $8.3 \%$ & $4.9 \%$ & $1.7 \%$ & $6.8 \%$ & $4.1 \%$ & $3.5 \%$ & $13.1 \%$ & $13.7 \%$ & $14.2 \%$ \\
\hline
\end{tabular}

\subsection{Driver Classification}

Driving technique is one of the main influences on fuel economy and emissions. Fuel economy of an MHEV is highly affected by the driver's tendencies, wherein an aggressive driver may yield worse fuel economy than a calm one. Other influencing factors include the chosen route and environmental effects including temperature and wind vector. The driver's behaviour is a controllable factor which would have the largest effect on fuel economy, as other parameters are largely dependent on external influences. Thus the driver can be classified quantitatively based on vehicle fuel consumption alone.

Driving style relates to the dynamic behaviour of a driver on the road. Different drivers navigate the same route using different styles. It is widely understood that aggressive, slow, and moderate driver modulation of the primary vehicle controls (throttle and brake) will each have different effects on the fuel consumption. The effects of later shift points and largerthan-necessary throttle openings on fuel consumption are well-understood and do not change depending on vehicle configuration. In an MT equipped vehicle, driving style can also be classified using the measure of the speed of gear changes. In this section, we show that using the shifting time alone, in our hybrid vehicle model we could observe a demonstrable change in vehicle performance and use this variable alone to characterise the driver. Because of the focus of our mild hybrid system on torque-filling, this variable was found to have a significant impact.

In this method, driver style classifications are defined using the average time to complete a gear change. This information is extracted from the speed profile. An average gear change time of less than one second is used to define an aggressive driver. Average times of between one and three seconds define normal driver styles, and more than three seconds define calm drivers $(62,63)$. For the purpose of this analysis, the gear change start is defined by the initial clutch pedal actuation, and the gear change end is defined as the application of steady-state throttle demand following the return of the clutch to its engaged position. Figure 11 shows the three different driver classifications graphically, presenting the speed and torque profile with different gear change period to define different styles.

Simulations are conducted on the previously used driving cycles. In these simulations, the drive cycle was kept constant and driver parameters varied. These parameters correspond to the shift time. Shift time was changed by varying the clutch aggressiveness, and the throttle aggressiveness. The aggressiveness of each element may be controlled by varying the rate of change of the actuation, which has a direct effect on system settling time. The parameters were varied to achieve driver behaviour consistent with our three classifications. The results are shown in Table 8, and illustrate that using our metric of gear shift time, the driver classified as calm was the most fuel efficient, and the aggressive driver was the least. This is 
consistent with other results and shows that the gear change time metric is a valid method for predicting driver influence on fuel economy. It also provides guidance for the development of a robotized gear shift in an AMT application, which is a longer-term goal of this body of work.
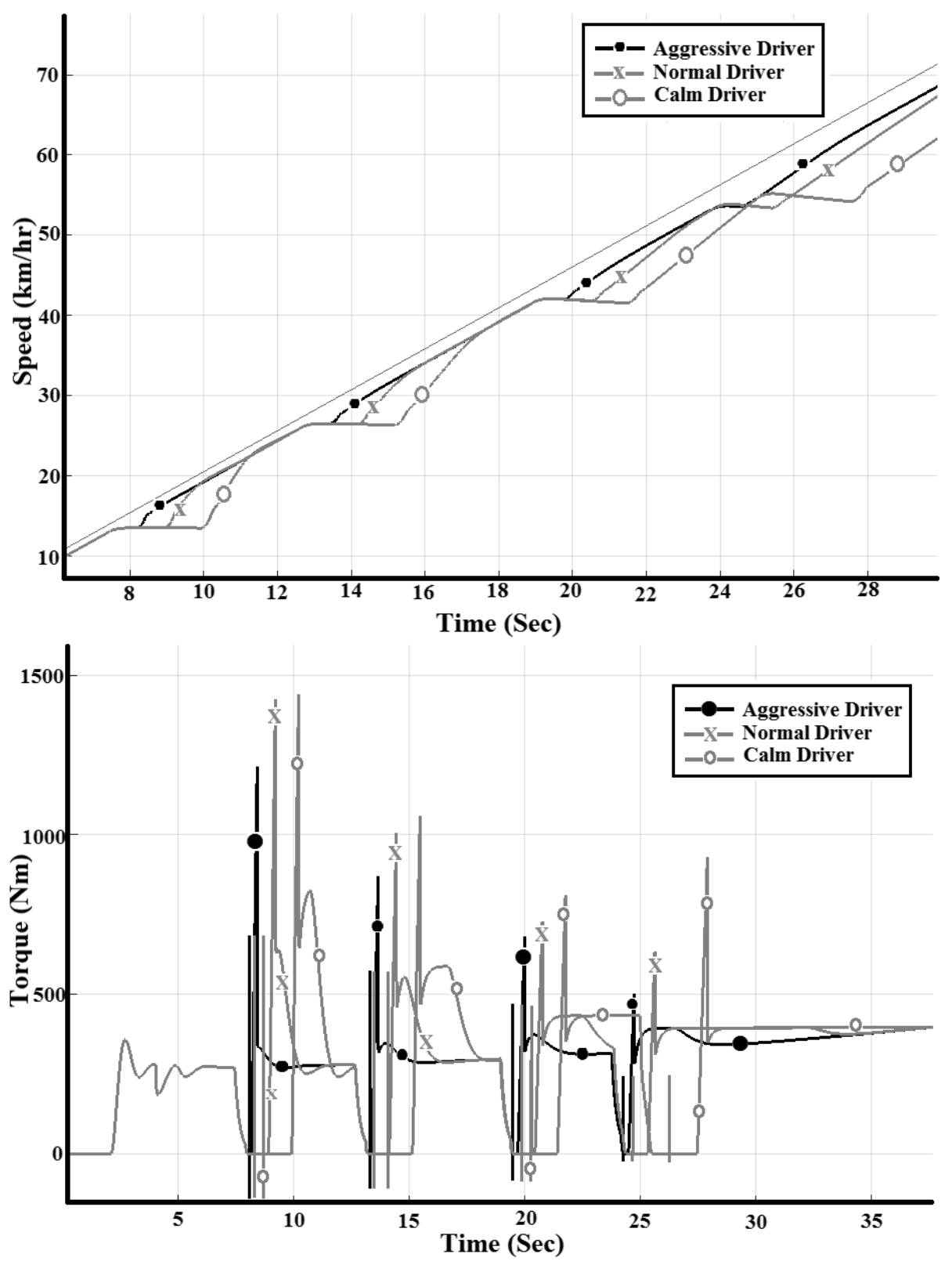

Figure 11. Speed and torque profile depending on Drive style

Table 8. Fuel Economics for conventional and Mild HEV by three driver styles.

\begin{tabular}{|c|c|c|c|c|c|c|c|c|c|}
\hline \multirow{2}{*}{$\begin{array}{c}\text { Drive } \\
\text { cycle }\end{array}$} & \multicolumn{8}{|c|}{ Fuel Economy (L/100 km) } \\
\cline { 2 - 10 } & \multicolumn{2}{|c|}{ Aggressive Driver } & \multicolumn{3}{c|}{ Normal Driver } & \multicolumn{3}{c|}{ Calm Driver } \\
\cline { 2 - 10 } & CV & MHEV & $\%$ & CV & MHEV & $\%$ & CV & MHEV & $\%$ \\
\hline NEDC & 7.9 & 7.6 & 3.8 & 8.3 & 7.9 & 4.8 & 9.1 & 8.2 & 10 \\
\hline UDDS & 8.1 & 7.4 & 8.6 & 8.6 & 7.7 & 10.5 & 10.3 & 8.6 & 16.5 \\
\hline NYCC & 17.6 & 16.98 & 3.5 & 19.8 & 18.8 & 5.1 & 21.2 & 20.3 & 4.2 \\
\hline
\end{tabular}




\section{Cost Analysis}

In order to validate our design decisions, a payback period must be calculated, taking into account the increased purchase price over the base vehicle. Manzie (48) accomplishes this using the total cost of ownership (TCO) methodology. In our case, this approach is not feasible for a number of reasons. Primarily there is significant regional variability in the published information that is available. For instance, to estimate operating costs, it is important to include government charges and service costs. However, the cost of labour and government regulation vary significantly from region to region, so it is difficult if not impossible to defend any estimation as accurate. Likewise, residual vehicle value depends on many variable parameters, such as new car tariffs, average national fleet age, and foreign exchange rate. Often in developing regions, the national average vehicle fleet age far exceeds that of Western countries. For instance, nearly $70 \%$ of vehicles registered in Egypt are over 15 years old (64), making residual value calculations based on the net present value method unreliable.

In general, a number of considerations are made with respect to the vehicle type, system configuration, annualised driving range, maintenance, and so on $(48,65,66)$. The result of this type of calculation procedure is an estimate of the lifecycle costs of a particular vehicle configuration. This has become a critical factor in the vehicle electrification debate as such vehicles typically have a much higher upfront cost than conventional internal combustion engine equivalents. For the purpose of this research, however, the considerations are significantly simplified. We have already adopted a particular vehicle configuration for the overall analysis (see section 1.1). Consequently, the baseline vehicles are identical, with the exception of the additional electrification equipment. Such Relative Cost of Ownership (RCO) models are typically applied to the comparison of alternative configuration arrangements(66) and are applicable here.

Specific to this paper, the relative cost of ownership can be calculated as follows:

$$
\begin{aligned}
& R C O=\{S P F \times(\text { glider }+ \text { engine }+ \text { transmission }+ \text { battery }+ \text { motor } \\
& + \text { Inverter }_{\mathrm{HEV}}+\text { Maintenance }_{\mathrm{HEV}}+\text { Total Range } \\
& \left.+ \text { Consumption }_{\mathrm{HEV}}-\text { Residual }_{\mathrm{HEV}}\right\} \\
& -\left\{S P F \times(\text { glider }+ \text { engine }+ \text { transmission })_{\text {ICEV }}\right.
\end{aligned}
$$

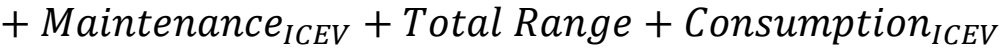

$$
\begin{aligned}
& \left.- \text { Residual }_{I C E V}\right\}
\end{aligned}
$$

Where SPF is sale price factor. As state, we are using identical vehicle configurations, with exception to the electrification components. Therefore the net vehicle cost between both configurations can be used. Also, as this is a mild hybrid vehicle, maintenance costs are assumed to be identical. Net fuel consumption can also be considered. Finally, based on the vehicle fleet profile of our target markets, it is reasonable to assume the vehicle will be held by the owner until it has no residual value. Therefore, the cost analysis simplifies to a payback period calculation. RCO can be simplified to:

$$
\begin{aligned}
R C O=S P F & \times\left(\text { battery }+ \text { motor }+ \text { Inverter }_{H E V}+\right.\text { Total Range } \\
& \times(\text { Consumption } \\
H E V & \left.- \text { Consumption }_{I C E V}\right)
\end{aligned}
$$




\subsection{Production Cost}

The production cost may be calculated by developing pricing using the power ratings of each element of the mild-hybrid powertrain, in line with $(67,68)$. This cost is then added to the cost of the base (ICE only) vehicle. Because the base vehicle is substantially identical to the mild hybrid version without the electric powertrain, it is not necessary to consider the cost of the base vehicle in the payback period calculation.

It is necessary to multiply the price difference by a "sale price factor", which includes both the retail mark-up and government charges that would be added to the sale price of a vehicle. In most cases, the retail mark-up is adjusted up or down by market forces to maintain parity with global prices despite total government charges. Therefore the use of a single factor is considered appropriate. The literature (48) cites 1.71 as a reasonable approximation.

A 5\% cost limit on the net manufacturing cost increase over the base vehicle is a primary design criterion. This value has been chosen as being representative of the typical variation that may be acceptable to the end consumer. The value covers the total cost of hybridization, included motor, inverter, and battery. The cost estimates for these components are presented below.

\subsection{Electric propulsion system (EPS)}

Various methods have been proposed for approximating the manufacturing cost based on physical performance requirements. McKeever (69) gives original equations (5),(6) for both the inverter and motor cost, however, because of the technological and scale improvements in the intervening period, they cannot be considered realistic in the current term.

$$
\begin{aligned}
& \text { Inverter cost }=\$ 418+\$ 7.60 \times \mathrm{kW} \text { peak } \\
& \text { Motor Cost }=\$ 33.33+\$ 10.6 \times \mathrm{kW} \text { peak }
\end{aligned}
$$

Hadley (67) proposes a near-term cost of US\$41 per rated $\mathrm{kW}$ for total motor and inverter cost. $\mathrm{Wu}(68)$ provides a compound annual growth rate (CAGR) for the capital cost of HEV components. For the motor/controller, the CAGR is $-4.4 \%$. By applying the CAGR to the figure proposed by Hadley (67), we arrive at a 2016 figure of US $\$ 31.30 / \mathrm{kW}$. Our motor and controller are therefore expected to add approximately US\$375.60 to the cost of the base vehicle.

\subsection{Battery}

In determining the battery capacity and size, the intent of the mild hybrid is to provide some of the benefits of hybrids at a low incremental cost. This intent is accomplished using a small battery pack $(70,71)$. Battery sizing may be calculated by assuming the vehicle is only operating in charge-sustaining mode. Charging is accomplished by selecting optimum times to run the engine at a higher load point than road-speed requires, using the excess power to drive the BLDC motor. $80 \%$ of the battery capacity is assumed to be available for tractive power. The component efficiency of the system was previously calculated at $85 \%$ for the motor and controller (40), and $81 \%$ coulombic efficiency was estimated. Multiplying these figures results in $69 \%$ total efficiency applied to both the charge and discharge cycles. Battery sizing is calculated using a discharge rate of $15 \mathrm{C}$ and a charge rate of $10 \mathrm{C}$, both of which are within the capabilities of typical NiMH batteries $(5,72)$. Tractive power demands of $10 \mathrm{~kW}$ maximum results in a required battery capacity of $0.968 \mathrm{kWh}$ to achieve $15 \mathrm{C}$ 
discharge. Using the NYCC cycle, a maximum required the regenerative braking power of $9.2 \mathrm{~kW}$ is calculated. The latter figure results in a required battery capacity of $0.633 \mathrm{kWh}$ for charging at $10 \mathrm{C}$. The larger calculated value should prove sufficient to power the vehicle under ideal conditions, but nominally $1.2 \mathrm{kWh}$ is used, to account for temperature effects and other losses in the absence of battery model specifications (73).

From (71), Based on available literature the cost of a $1.2 \mathrm{kWh}$ battery is estimated at US\$60, the total system cost is therefore US $\$ 436$. The intention is to create a system suitable for vehicles sold in developing markets that will reduce air pollutants produced by the vehicle in regions with typically poor urban air quality (29). It will also reduce dependency on fossil fuels for such regions. However, as these costs breach the pre-defined upper limits, further study of overall costs and cost saving measures is required to reach the goal.

\subsection{Payback Period}

The cost difference of US $\$ 435.60$ is multiplied by the sale price factor of 1.71 to arrive at a retail price difference of US\$744.86. This figure was used as the basis for the payback calculation. An average fuel price of US $\$ 1.50$ per litre was also used, as was an annual distance travelled of $15,000 \mathrm{~km}(74)$.

The results shown in Table 8 were then used to calculate a payback period in years, which is shown in Table 9. The calm driver yielded the shortest payback period, of 2-4 years, whereas the aggressive driver yielded a much greater payback period of 5.5 to 11 years, dependent upon the drive cycle used for the analysis. Using a weighted average of $40 \%$ NEDC and $60 \%$ NYCC cycles, which may be more representative of a realistic driving pattern, the calm driver broke even in 3.6 years whereas the aggressive driver broke even in 6.8 years. In every case, however, the payback period does not exceed the typical vehicle lifetime, which is greater than 15 years. The results suggest that our low-cost mild-hybrid powertrain is effective, though particularly susceptible to driver influence.

Table 9. Payback period in years.

\begin{tabular}{|c|c|c|c|}
\hline \multirow{2}{*}{} & \multicolumn{3}{|c|}{ Payback 15,000 km } \\
\cline { 2 - 4 } & Aggressive Driver & Normal Driver & Calm Driver \\
\hline NEDC & 11 & 8.2 & 3.6 \\
\hline UDDS & 4.7 & 3.6 & 1.9 \\
\hline NYCC & 5.3 & 3.3 & 3.6 \\
\hline \multirow{2}{*}{ Weighted average years } & 6.7 & 4.3 & 3.6 \\
\hline
\end{tabular}

\section{CONCLUSION}

This paper has introduced a cost-effective mild hybrid electric powertrain for a MT vehicle, integrating an EM to provide improved fuel economy, drivability and comfort by reducing torque holes during gear shifts. The adoption of the motor has required the development of vehicle control strategies to manage power split under a range of driving conditions, and a gear shifting strategy to control transient vibration during and after gearshift.

Our stated goal in undertaking this design study is to develop an ultra-low-cost mild hybrid drive system for B-segment, light-duty vehicles offered in less sophisticated markets, due to 
the correlation these markets share geographically with areas affected by high atmospheric pollutant levels $(75,76)$. In developing a product for these markets, we have identified key design characteristics (in particular, driving characteristics such as shift quality, commercial characteristics contributing to manufacturing cost) that should be met, and we have investigated ways of maximising the fulfilment of these goals. The MHEV configuration proposed simplifies the vehicle architecture over and above that described in the prior literature, to achieve desired performance using only one EM. This is achieved through the application of a superior EMS that balances driving needs with SOC and other conditions. This simplification reduces overall weight and cost. Despite our focus on minimising added cost, any increase in cost over the cost to produce the equivalent ICE-powered vehicle must be compensated through other means, such as fuel or tax savings. We have quantified the inherent cost of ownership savings made by adoption of the mild hybrid drive.

Our results and discussion indicate that the vehicle design goals we have specified are reasonable in a production setting. Benchmarking and Simulation suggest that fuel economy is mildly improved in line with expectations and that emissions are reduced, in some cases significantly. This potential for significant reductions in emissions as well as the achievement of low operating and manufacturing costs reinforces our view that such a vehicle design has the potential for significant socio-environmental impact in the target market.

\section{ACKNOWLEDGMENT}

The financial support of this work by the Australian Research Council (DP150102751), Excellerate Australia (1-210) and the University of Technology Sydney, is gratefully acknowledged.

\section{Definitions/Abbreviations}

\begin{tabular}{|l|l|}
\hline HEV & Hybrid Electric Vehicles \\
\hline $\begin{array}{l}\text { NYCDDS, } \\
\text { NYCC }\end{array}$ & $\begin{array}{l}\text { the New York City Dynamometer Drive } \\
\text { Schedule, New York City Cycle }\end{array}$ \\
\hline NiMH & Nickel Metal Hydride \\
\hline UDDS & Dynamometer Drive Schedule \\
\hline NEDC & New European Drive Cycle \\
\hline VDV & Vibration dose value \\
\hline ICE & Internal Combustion Engine \\
\hline CV & Conventional Vehicle \\
\hline MHEV & Mild Hybrid Electric Vehicle \\
\hline BLDC & Brushless DC Motor \\
\hline MT & Manual Transmission \\
\hline EM & Electric Machine \\
\hline DCT & Dual-Clutch Transmission \\
\hline AMT & Automated manual transmission \\
\hline CVT & Continuously Variable Transmission \\
\hline GHG & Greenhouse Gas Emissions \\
\hline SOC & The State of Charge \\
\hline DOF & Degree-of-Freedom \\
\hline & \\
\hline
\end{tabular}




\begin{tabular}{|l|l|}
\hline CO & Carbon Monoxide \\
\hline HC & Hydrocarbons \\
\hline NOx & Oxides of Nitrogen \\
\hline PM & Particulate Matter \\
\hline RCO & Relative Cost of Ownership \\
\hline SPF & Sale Price Factor \\
\hline
\end{tabular}

\section{References}

1. Jeon S-i, Jo S-t, Park Y-i, Lee J-m. Multi-Mode Driving Control of a Parallel Hybrid Electric Vehicle Using Driving Pattern Recognition. Journal of Dynamic Systems, Measurement, and Control. 2000;124(1):141-9.

2. Miller MA, Holmes AG, Conlon BM, Savagian PJ. The GM "Voltec" 4ET50 MultiMode Electric Transaxle. SAE Int J Engines. 2011;4(1):1102-14.

3. Carello M, Bonansea P, D'Auria M. Driveline Optimization for a Hybrid Electric City Vehicle to Minimize Fuel Consumption. SAE International; 2014.

4. Semel RR. Fuel Economy Improvements through Improved Automatic Transmission Warmup - Stand Alone Oil to Air (OTA) Transmission Cooling Strategy with Thermostatic Cold Flow Bypass Valve. SAE International; 2001.

5. Tie SF, Tan CW. A review of energy sources and energy management system in electric vehicles. Renewable and Sustainable Energy Reviews. 2013;20:82-102.

6. OECD. The Cost of Air Pollution: OECD Publishing; 20142014.

7. Organization WH. WHO's Ambient Air Pollution database: Update 2014. Ginebra, Suiza: World Health Organization (WHO). 2014.

8. Bilgin B, Magne P, Malysz P, Yang Y, Pantelic V, Preindl M, et al. Making the case for electrified transportation. IEEE Transactions on Transportation Electrification. 2015;1(1):4-17.

9. Baraszu RC, Cikanek SR, editors. Torque fill-in for an automated shift manual transmission in a parallel hybrid electric vehicle. Proceedings of the 2002 American Control Conference (IEEE Cat NoCH37301); 2002 8-10 May 2002: IEEE.

10. Rahman Z, Butler KL, Ehsani M. A comparison study between two parallel hybrid control concepts. Development. 2000;1:0978.

11. Aoki K, Kuroda S, Kajiwara S, Sato H, Yamamoto Y. Development of integrated motor assist hybrid system: development of the'insight', a personal hybrid coupe. Honda $\mathrm{R}$ and D Co., Ltd.(US); 2000.

12. Chan $C$. The state of the art of electric and hybrid vehicles. Proceedings of the IEEE. 2002;90(2):247-75.

13. Ehsani M, Gao Y, Miller JM. Hybrid electric vehicles: Architecture and motor drives. Proceedings of the IEEE. 2007;95(4):719-28.

14. Niasar AH, Moghbelli H, Vahedi A, editors. Design methodology of drive train for a series-parallel hybrid electric vehicle (SP-HEV) and its power flow control strategy. IEEE International Conference on Electric Machines and Drives, 2005; 2005: IEEE.

15. Kim TS, Manzie C, Watson H. Fuel economy benefits of look-ahead capability in a mild hybrid configuration. IFAC Proceedings Volumes. 2008;41(2):5646-51.

16. McGehee J, Yoon H-S. Optimal torque control of an integrated starter-generator using genetic algorithms. Proceedings of the Institution of Mechanical Engineers, Part D: Journal of Automobile Engineering. 2015;229(7):875-84. 
17. Galvagno E, Velardocchia M, Vigliani A. Analysis and simulation of a torque assist automated manual transmission. Mechanical Systems and Signal Processing. 2011;25(6):1877-86.

18. Awadallah M, Tawadros P, Walker P, Zhang N, editors. Eliminating the torque hole: Using a mild hybrid EV architecture to deliver better driveability. 2016 IEEE Transportation Electrification Conference and Expo, Asia-Pacific (ITEC Asia-Pacific); 2016 June 1-4, 2016; Busan, South Korea: IEEE.

19. Awadallah M, Tawadros P, Walker P, Zhang N. Comparative System Dynamic Modeling of a Conventional and Hybrid Electric Powertrain. In: Datong Qin YS, editor. Power Engineering - International conference on Power Transmissions (ICPT 2016). Chongqing, China: CRC Press; 2016. p. 231-8.

20. Awadallah M, Tawadros P, Walker P, Zhang N. Dynamic modelling and simulation of a manual transmission based mild hybrid vehicle. Mechanism and Machine Theory. 2017;112:218-39.

21. Li Y, Liu M, Lau J, Zhang B. A novel method to determine the motor efficiency under variable speed operations and partial load conditions. Applied Energy. 2015;144:23440 .

22. Di Nicola F, Sorniotti A, Holdstock T, Viotto F, Bertolotto S. Optimization of a multiple-speed transmission for downsizing the motor of a fully electric vehicle. SAE International Journal of Alternative Powertrains. 2012;1(2012-01-0630):134-43.

23. Zeraoulia M, Benbouzid MEH, Diallo D. Electric motor drive selection issues for HEV propulsion systems: A comparative study. Vehicular Technology, IEEE Transactions on. 2006;55(6):1756-64.

24. Sharma S, Kumar V. Optimized Motor Selection for Various Hybrid and Electric Vehicles. SAE Technical Paper; 2013.

25. Chang L. Comparison of AC drives for electric vehicles-a report on experts' opinion survey. Aerospace and Electronic Systems Magazine, IEEE. 1994;9(8):7-11.

26. Wagner U, Wagner A. Electrical Shift Gearbox (ESG) - Consistent Development of the Dual Clutch Transmission to a Mild Hybrid System. SAE International; 2005.

27. Rahmat MS, Ahmad F, Yamin AKM, Aparow VR, Tamaldin N. Modelling and Torque Tracking Control of Permanent Magnet Synchronous Motor for Hybrid Electric Vehicles. International Journal of Automotive and Mechanical Engineering. 2013;7:955.

28. Liu Z, Ivanco A, Filipi ZS. Impacts of Real-World Driving and Driver Aggressiveness on Fuel Consumption of 48V Mild Hybrid Vehicle. SAE International Journal of Alternative Powertrains. 2016;5(2016-01-1166).

29. Hutchinson T, Burgess S, Herrmann G. Current hybrid-electric powertrain architectures: Applying empirical design data to life cycle assessment and whole-life cost analysis. Applied Energy. 2014;119:314-29.

30. Jung D, Cho S, Park S, Min K. Application of a modified thermostatic control strategy to parallel mild HEV for improving fuel economy in urban driving conditions. International Journal of Automotive Technology. 2016;17(2):339-46.

31. Salisa AR, Zhang N, Zhu J. A comparative analysis of fuel economy and emissions between a conventional HEV and the UTS PHEV. IEEE Transactions on Vehicular Technology. 2011;60(1):44-54.

32. Awadallah M, Tawadros P, Walker P, Zhang N, editors. A Comparative Fuel Analysis of a novel HEV with conventional vehicle. Vehicular Technology Conference (VTC Spring), 2017 IEEE 85th; 2017 June 4-7, 2017; Sydney, Australia: IEEE.

33. Torres J, Gonzalez R, Gimenez A, Lopez J. Energy management strategy for plug-in hybrid electric vehicles. A comparative study. Applied Energy. 2014;113:816-24. 
34. Ruan J, Walker P, Zhang N, Xu G. The Safety and Dynamic Performance of Blended Brake System on a Two-Speed DCT Based Battery Electric Vehicle. SAE International Journal of Passenger Cars-Mechanical Systems. 2016;9(2016-01-0468):143-53.

35. Takao K, Toshihiko H. Vehicle Development through "Kansei" Engineering. SAE Technical Paper; 2003. Report No.: 0148-7191.

36. Honey E, Suh I-S. A feasibility study of an electric-hydraulic hybrid powertrain for passenger vehicles. Proceedings of the Institution of Mechanical Engineers, Part D: Journal of Automobile Engineering. 2015;229(14):1894-906.

37. Borhan HA, Vahidi A, Phillips AM, Kuang ML, Kolmanovsky IV, editors. Predictive energy management of a power-split hybrid electric vehicle. American Control Conference, 2009 ACC'09; 2009: IEEE.

38. Hartani K, Miloud Y, Miloudi A. Improved direct torque control of permanent magnet synchronous electrical vehicle motor with proportional-integral resistance estimator. Journal of Electrical Engineering and Technology. 2010;5(3):451-61.

39. Awadallah $M$, Tawadros $P$, Walker $P$, Zhang $N$, editors. Selection and Characterisation of PMSM motor for mild HEV Applications. 29th Electric Vehicle Symposium 2016 (EVS29); 2016 June 19-22, 2016; Montréal, Québec, Canada: Electric Drive Transportation Association ( EDTA ).

40. Awadallah M, Tawadros P, Zhang N, editors. Rapid Prototyping and Validation of Mars 0913 Brushless Motor to Develop Mild HEV. The 7th TM Symposium China (TMC2015); 2015 April 23-24; Shanghai, China: SAE-China; 2015.

41. Zhou Z, Zhang J, Xu L, Guo Z, editors. Modeling and simulation of hydromechanical continuously variable transmission system based on Simscape. Advanced Mechatronic Systems (ICAMechS), 2015 International Conference on; 2015: IEEE.

42. Mahapatra S, Egel T, Hassan R, Shenoy R, Carone M. Model-based design for hybrid electric vehicle systems. SAE Technical Paper; 2008. Report No.: 0148-7191.

43. Awadallah M, Tawadros P, Walker P, Zhang N, editors. A Low-Cost and Novel Approach in Gearshift Control for a Mild-Hybrid Powertrain. IEEE Transportation Electrification Conference and Expo (ITEC), 2017 IEEE; 2017 June 22-24, 2017; Chicago, Illinois, USA: IEEE.

44. Ruan J, Walker P. An Optimal Regenerative Braking Energy Recovery System for Two-Speed Dual Clutch Transmission-Based Electric Vehicles. SAE International; 2014.

45. Wei Z, Xu J, Halim D. HEV power management control strategy for urban driving. Applied Energy. 2016.

46. Chiara F, Canova M. A review of energy consumption, management, and recovery in automotive systems, with considerations of future trends. Proceedings of the Institution of Mechanical Engineers, Part D: Journal of Automobile Engineering. 2013;227(6):914-36.

47. Awadallah M, Tawadros P, Walker P, Zhang N, editors. Impact of Low and High Congestion Traffic Patterns on a Mild-HEV Performance. SAE 2017 International Powertrains, Fuels \& Lubricants Meeting; 2017 2017-10-16; Beijing, China: SAE Technical Paper.

48. Sharma R, Manzie C, Bessede M, Brear M, Crawford R. Conventional, hybrid and electric vehicles for Australian driving conditions-Part 1: Technical and financial analysis. Transportation Research Part C: Emerging Technologies. 2012;25:238-49.

49. Amrhein M, Krein PT. Dynamic simulation for analysis of hybrid electric vehicle system and subsystem interactions, including power electronics. IEEE transactions on vehicular technology. 2005;54(3):825-36.

50. Markel T, Brooker A, Hendricks T, Johnson V, Kelly K, Kramer B, et al. ADVISOR: a systems analysis tool for advanced vehicle modeling. Journal of power sources. 2002;110(2):255-66. 
51. Baisden AC, Emadi A. ADVISOR-based model of a battery and an ultra-capacitor energy source for hybrid electric vehicles. IEEE Transactions on Vehicular Technology. 2004;53(1):199-205.

52. Oh SC. Evaluation of motor characteristics for hybrid electric vehicles using the hardware-in-the-loop concept. IEEE transactions on vehicular technology. 2005;54(3):81724.

53. Manzie C, Watson H, Halgamuge S, Lim K. A comparison of fuel consumption between hybrid and intelligent vehicles during urban driving. Proceedings of the Institution of Mechanical Engineers, Part D: Journal of Automobile Engineering. 2006;220(1):67-76.

54. Manzie C, Watson H, Halgamuge S. Fuel economy improvements for urban driving: Hybrid vs. intelligent vehicles. Transportation Research Part C: Emerging Technologies. 2007;15(1):1-16.

55. Weissler P. Many factors figure in fuel-economy calculation for electric vehicles. Automotive Engineering International. 2009.

56. Mazloomi K, Gomes C. Hydrogen as an energy carrier: prospects and challenges. Renewable and Sustainable Energy Reviews. 2012;16(5):3024-33.

57. Hawkins TR, Gausen OM, Strømman AH. Environmental impacts of hybrid and electric vehicles - a review. The International Journal of Life Cycle Assessment. 2012;17(8):997-1014.

58. Butler KL, Ehsani M, Kamath P. A Matlab-based modeling and simulation package for electric and hybrid electric vehicle design. IEEE Transactions on vehicular technology. 1999;48(6):1770-8.

59. Ao G, Qiang J, Zhong H, Mao X, Yang L, Zhuo B. Fuel economy and NO x emission potential investigation and trade-off of a hybrid electric vehicle based on dynamic programming. Proceedings of the Institution of Mechanical Engineers, Part D: Journal of Automobile Engineering. 2008;222(10):1851-64.

60. Johnson VH, Wipke KB, Rausen DJ. HEV control strategy for real-time optimization of fuel economy and emissions. SAE transactions. 2000;109(3):1677-90.

61. Fontaras G, Pistikopoulos P, Samaras Z. Experimental evaluation of hybrid vehicle fuel economy and pollutant emissions over real-world simulation driving cycles. Atmospheric environment. 2008;42(18):4023-35.

62. Murphey YL, Milton R, Kiliaris L, editors. Driver's style classification using jerk analysis. Computational Intelligence in Vehicles and Vehicular Systems, 2009 CIVVS'09 IEEE Workshop on; 2009: IEEE.

63. Lee S, Choi J, Jeong K, Kim H. A Study of Fuel Economy Improvement in a Plug-in Hybrid Electric Vehicle using Engine on/off and Battery Charging Power Control Based on Driver Characteristics. Energies. 2015;8(9):10106-26.

64. Waked A, Afif C. Emissions of air pollutants from road transport in Lebanon and other countries in the Middle East region. Atmospheric environment. 2012;61:446-52.

65. Contestabile M, Alajaji M, Almubarak B. Will current electric vehicle policy lead to cost-effective electrification of passenger car transport? Energy Policy. 2017;110:20-30.

66. Bishop JD, Martin NP, Boies AM. Cost-effectiveness of alternative powertrains for reduced energy use and CO 2 emissions in passenger vehicles. Applied Energy. 2014;124:4461.

67. Hadley SW, Cleary TP. Plug-in Hybrid Electric Vehicle Value Proposition StudyFinal Report. 2010.

68. Wu G, Inderbitzin A, Bening C. Total cost of ownership of electric vehicles compared to conventional vehicles: A probabilistic analysis and projection across market segments. Energy Policy. 2015;80:196-214. 
69. McKeever JW, Das S, Tolbert LM, Marlino LD, Nedungadi A. Life-Cycle Cost Sensitivity to Battery-Pack Voltage of an HEV. Life. 2000;1:1556.

70. Sharma R, Bessede M, Manzie C, Brear M, Crawford R. An Economic and In-Service Emissions Analysis of Conventional, Hybrid and Electric Vehicles for Australian Driving Conditions. SAE International Journal of Commercial Vehicles. 2012;5(1):291-8.

71. Brown P, Jackson N, Sykes L, Wheals J, Wiseman M. A Hybrid and Fuel Cell Vehicle Future? : SAE Technical Paper; 2002. Report No.: 0148-7191.

72. Karden E, Ploumen S, Fricke B, Miller T, Snyder K. Energy storage devices for future hybrid electric vehicles. Journal of Power Sources. 2007;168(1):2-11.

73. Awadallah M, Tawadros P, Walker P, Zhang N, editors. A System Analysis and Modeling of a HEV based on Ultracapacitor Battery. IEEE Transportation Electrification Conference and Expo (ITEC), 2017 IEEE; 2017 June 22-24, 2017; Chicago, Illinois, USA: IEEE.

74. Walker PD, Roser HM. Energy consumption and cost analysis of hybrid electric powertrain configurations for two wheelers. Applied Energy. 2015;146:279-87.

75. Smith KR. Fuel combustion, air pollution exposure, and health: the situation in developing countries. Annual Review of Energy and the Environment. 1993;18(1):529-66.

76. Campbell-Lendrum D, Corvalán C. Climate change and developing-country cities: implications for environmental health and equity. Journal of Urban Health. 2007;84(1):10917. 